OPEN ACCESS

Edited by:

Eng-King Tan,

National Neuroscience Institute

(NNI), Singapore

Reviewed by:

Luan Pereira Diniz,

Federal University of Rio de

Janeiro, Brazi

Daniel Erny,

University of Freiburg Medical

Center, Germany

*Correspondence:

Zhong-Ping Feng zp.feng@utoronto.ca

Specialty section:

This article was submitted to Non-Neuronal Cells,

a section of the journal

Frontiers in Cellular Neuroscience

Received: 19 October 2020 Accepted: 17 December 2020 Published: 18 January 2021

Citation:

Steinman J, Sun HS and Feng ZP (2021) Microvascular Alterations in Alzheimer's Disease. Front. Cell. Neurosci. 14:618986 doi: 10.3389/fncel.2020.618986

\section{Microvascular Alterations in Alzheimer's Disease}

\author{
Joe Steinman ${ }^{1}$, Hong-Shuo Sun ${ }^{1,2}$ and Zhong-Ping Feng ${ }^{1 *}$ \\ ${ }^{1}$ Department of Physiology, University of Toronto, Toronto, ON, Canada, ${ }^{2}$ Department of Surgery, University of Toronto, \\ Toronto, ON, Canada
}

Alzheimer's disease (AD) is a neurodegenerative disorder associated with continual decline in cognition and ability to perform routine functions such as remembering familiar places or understanding speech. For decades, amyloid beta $(A \beta)$ was viewed as the driver of $A D$, triggering neurodegenerative processes such as inflammation and formation of neurofibrillary tangles (NFTs). This approach has not yielded therapeutics that cure the disease or significant improvements in long-term cognition through removal of plaques and $A \beta$ oligomers. Some researchers propose alternate mechanisms that drive $A D$ or act in conjunction with amyloid to promote neurodegeneration. This review summarizes the status of $A D$ research and examines research directions including and beyond $A \beta$, such as tau, inflammation, and protein clearance mechanisms. The effect of aging on microvasculature is highlighted, including its contribution to reduced blood flow that impairs cognition. Microvascular alterations observed in AD are outlined, emphasizing imaging studies of capillary malfunction. The review concludes with a discussion of two therapies to protect tissue without directly targeting $A \beta$ for removal: (1) administration of growth factors to promote vascular recovery in AD; (2) inhibiting activity of a calcium-permeable ion channels to reduce microglial activation and restore cerebral vascular function.

\section{Keywords: Alzheimer's disease, amyloid hypotheses, vasculature, microvasculature, TRPM2, angiogeneis, growth factors, imaging}

\section{PREFACE}

Many drugs developed to treat Alzheimer's disease (AD) have been designed on the assumption that amyloid beta $(\mathrm{A} \beta)$ drives the disease. This approach has not yielded FDA-approved drugs, with approved medications such as cholinesterase inhibitors or memantine (glutamate blocker) only treating symptoms of AD. Proponents of the Amyloid Hypothesis (AH) feel that anti-A $\beta$ therapies may have been administered too late in the disease process, and that the $\mathrm{AH}$ remains valid. To others, disease mechanisms beyond $\mathrm{A} \beta$ accumulation must be targeted.

Movement beyond traditional interpretations of the $\mathrm{AH}$ requires understanding the myriad of processes altered in $\mathrm{AD}$. This influences research direction and treatment development. This review summarizes the status of $\mathrm{AD}$ research, and includes the examination and discussion of multiple mechanisms underlying $\mathrm{AD}$ pathology. Alternative hypotheses of $\mathrm{AD}$ beyond the $\mathrm{AH}$, such as abnormal tau and inflammation, are detailed. Microvascular alterations in aging and AD are discussed, and their role assessed in reducing blood flow and impairing $A \beta$ clearance from tissue. Techniques and methods for imaging microvasculature in $\mathrm{AD}$ are outlined, with results from studies highlighting the role of capillary imaging and mathematical analysis in understanding vascular contributions to $A D$. The review concludes by discussing potential therapies that promote vascular recovery and protection against $\mathrm{A} \beta$ toxicity without targeting $\mathrm{A} \beta$. 


\section{INTRODUCTION: AN OVERVIEW}

$\mathrm{AD}$ is associated with decline in episodic memory, impaired concentration or attention, disorientation, and loss of verbal fluency (Vandenberghe and Tournoy, 2005; Ferris and Farlow, 2013). Examples of factors contributing to loss of cognition include age-related capillary reductions and blood brain barrier (BBB) leakage (Farkas and Luiten, 2001; Zlokovic, 2005), release of pro-inflammatory cytokines from microglia that induce neuron death (Floden et al., 2005; Wang et al., 2015), plaqueinduced neural network disruption (Knowles et al., 1999; Kuchibhotla et al., 2008), and toxic soluble $A \beta$ oligomers that cause synaptic dysfunction (Smith and Strittmatter, 2017).

The $\mathrm{AH}$ proposes that extracellular $\mathrm{A} \beta$ deposition initiates neurodegenerative processes, such as neurofibrillary tangle (NFT) formation, leading to cognitive impairment (Hardy and Higgins, 1992; Makin, 2018). It was initially believed that elimination of plaques via targeting $\mathrm{A} \beta$ would improve cognition. This was supported by promising results in transgenic PDAPP mice overexpressing mutant human APP, where immunization with $\mathrm{A} \beta$ prevented plaque development and neurite damage (Schenk et al., 1999).

Current treatments, such as cholinesterase inhibitors, temporarily improve symptoms such as memory loss and reasoning capacity, without altering $\mathrm{A} \beta$ deposition or tau pathology (Govindpani et al., 2019; Madav et al., 2019). By passage of 3 months, the effect of these treatments is reduced due to tolerance development in patients (Madav et al., 2019).

One possibility for developing $\mathrm{AD}$ treatments is targeting multiple therapeutic sites in addition to, or separately from, $A \beta$ (Selkoe, 2019). This could enable use of approved medications developed to treat other conditions. For example, a recent study that applied etodolac (a nonsteroidal anti-inflammatory) to an in vitro $\mathrm{AD}$ cell culture model found enhanced $\mathrm{BBB}$ integrity and reduced cell death in response to neurotoxins (thrombin) administered into the endothelial cell barrier (Shin et al., 2019).

Targeting multiple therapeutic sites in addition to $\mathrm{A} \beta$ requires understanding the complexity of $\mathrm{AD}$ pathology and numerous changes that occur possibly independent of $A \beta$. For example, $\mathrm{BBB}$ dysfunction may occur prior to $\mathrm{A} \beta$ deposition in individuals possessing the apolipoprotein $\mathrm{E} 4$ gene (ApoE4), where the ApoE4 gene is known to render susceptibility to AD (Montagne et al., 2020). Tau, a microtubule associated protein linked to synaptic loss and dysfunction, is more closely related to cognitive impairment than amyloid (Bejanin et al., 2017). Susceptibility to $\mathrm{AD}$ may be dependent on gender, with women twice as likely as men to contact $\mathrm{AD}$. This is possibly due to metabolic alterations during menopause (Ferretti et al., 2018). Microglia, central nervous system (CNS) immune cells, may operate protectively by surrounding amyloid deposits, compacting fibrils into a less toxic form and preventing plaque growth. They may also harm neurons through release of inflammatory mediators (Hansen et al., 2018). This dual role highlights the complexity of the tissue response to $\mathrm{AD}$.

Often overlooked in Alzheimer's research is the microvasculature, which is commonly viewed as secondary to neuronal death and inflammation. Recent microscopy studies suggest a critical role of the microvasculature in disease progression. Cruz Hernández et al. (2019) demonstrated via vascular and neutrophil imaging with 2-photon microscopy in $\mathrm{AD}$ mice and mathematical blood flow modeling (in mouse, human, and synthetic microvascular networks) that capillary flow blockage via neutrophils reduces cerebral blood flow (CBF). $\mathrm{CBF}$ was restored through antibody targeting of neutrophils, which improved short-term memory function up to 16-months of age in APP/PS1 mice (Bracko et al., 2020). Nortley et al. (2019) demonstrated capillary compression by pericytes induced by amyloid-triggered release of endothelin could lead to widespread reductions in blood flow. These findings suggest the microvasculature could contribute to damage of brain cells and synapses (Nortley et al., 2019).

Consideration of aspects of the disease beyond amyloid are necessary for the development of therapies. The following section discusses the $\mathrm{AH}$ and presents alternatives. Microvascular changes and their contributions to $\mathrm{AD}$ follow. The review concludes by discussing two therapies that do not target $A \beta$ directly: (1) vascular endothelial growth factor (VEGF) administration to improve vascular survival (Religa et al., 2013); (2) inhibiting the calcium-permeable ion channel transient receptor potential melastatin 2 (TRPM2) to protect against $A \beta$ toxicity (Ostapchenko et al., 2015).

\section{ALZHEIMER'S RESEARCH: THE AMYLOID HYPOTHESIS}

\section{Alzheimer's Research: A General Summary}

Although the AH influenced and directed drug development for many years, there has been a shift in opinion toward exploring alternatives. Up to 2019, $22 \%$ of clinical trials tested amyloid therapies, while significant research efforts are focused on a range of targets such as neurotransmitters and tau (Liu et al., 2019).

Promising results have been obtained with anti- $A \beta$ strategies. Aducanumab, a human monoclonal antibody directed against $A \beta$, reduced soluble and insoluble parenchymal $A \beta$ in Tg2576 $\mathrm{AD}$ mice, while reducing $\mathrm{A} \beta$ in humans and slowing clinical decline (Sevigny et al., 2016). However, Aducanumab provided insufficient relief from functional and cognitive decline in two Phase 3 clinical trials, though subsequent analyses indicated reduced rate of behavioral and cognitive decline (Walsh and Selkoe, 2020). Another antibody, BAN2401 cleared amyloid plaques and slowed cognitive decline in a Phase $2 \mathrm{~b}$ study (Walsh and Selkoe, 2020).

Despite the promise of these anti-A $\beta$ therapeutics, it is unclear whether removal of amyloid by itself would "cure" AD. For example, widespread inflammation may be initiated by $\mathrm{A} \beta$ deposition, limiting the benefits of amyloid removal if inflammation is not simultaneously reduced. Aging reduces capillary density and blood flow, which may contribute to cognitive deficits alongside amyloid. According to the Mitochondrial Cascade Hypothesis, genetically, and environmentally determined decline in mitochondrial function triggers AD pathology (Swerdlow et al., 2014). In this instance, $\mathrm{A} \beta$ removal may only marginally improve $\mathrm{AD}$ (Swerdlow et al., 
2014). Some researchers contend neural network function is a better predictor of disease progression when compared with plaques (Kosik, 2013). These disparate views indicate a lack of consensus in treating or detecting $\mathrm{AD}$ and could be attributable to the wide variety of mechanisms which initiate $\mathrm{AD}$ and aid its progression. Genetic risks associated with $\mathrm{AD}$ may be related to APP production and processing, as well as other processes such as the immune system and neuroinflammation (Bertram and Tanzi, 2019). A single intervention targeting $A \beta$ removal may therefore be unable to significantly reverse disease progression.

\section{The Amyloid Hypothesis}

APP is a transmembrane protein processed by enzymes $\beta$ - and $\gamma$-secretase in the amyloidogenic pathway (Stakos et al., 2020). The length of the $A \beta$ peptide produced by this cleavage is 3842 amino acids, depending on the position where $\gamma$-secretase cleaves APP. It is largely the 42 -amino acid peptide that aggregates into soluble oligomers, ultimately coalescing into extracellular plaques.

According to the $\mathrm{AH}$, overproduction of APP or failure of clearance mechanisms causes amyloid accumulation (Mucke, 2009). As A $\beta$ concentration increases, oligomers are formed, followed by plaques. Oligomers alter cell signaling and trigger release of toxic molecules by microglia. Oligomers and dimers prevent glutamate reuptake by astrocytes and neurons, leading to excitotoxicity, while plaques distort and damage axons and dendrites (Mucke, 2009; Selkoe, 2019; Zott et al., 2019). Tangle formation is due to $\mathrm{A} \beta$ activation of kinases catalyzing tau phosphorylation, neuroinflammation and cytokine release, reduced ability to degrade tau, and $A \beta$-induced impaired axonal transport (Blurton-Jones and Laferla, 2006; Silva et al., 2019).

Genetic evidence supports the AH. Mutations in three genes, $A P P, P S E N 1$, and PSEN2, contribute to early-onset AD. The $A P P$ gene encodes the amyloid precursor protein, while PSEN1 and PSEN2 encode presenilins (Lanoiselée et al., 2017). Genetic variants influencing $A \beta$ and APP processing are also associated with later-onset dementia (dementia after 65) (Kunkle et al., 2019).

Mice models which overexpress APP develop plaques and memory impairment, but not NFTs. This may be due to absence of human tau in some mouse models (Selkoe and Hardy, 2016). Choi et al. (2014) demonstrated in human neural cell culture that mutations in APP and PSEN1 produced extracellular amyloid plaques and tau pathology. Amyloid and tau were reduced through administration of $\beta$ - or $\gamma$-secretase inhibitors, indicating that targeting $\mathrm{A} \beta$ peptide generation reduces plaques and tangles (Choi et al., 2014).

Further evidence in favor of the $\mathrm{AH}$ is described in Walsh and Selkoe (2020) and Selkoe and Hardy (2016). In Down's Syndrome an additional copy of Chromosome 21 produces an extra APP gene, causing the individual to display AD-like neuropathology. This is followed by microgliosis (proliferation and migration of microglia), astrocytosis (astrocyte proliferation in response to brain damage), and NFTs (Selkoe and Hardy, 2016). In contrast, mutations which reduce amyloid deposition protect against AD (Selkoe and Hardy, 2016). In general, early inherited $\mathrm{AD}$ is caused by APP mutations or in the proteins generating
APP. These mutations, and corresponding biomarkers such as CSF A $\beta$ concentration, may precede other pathologies including tau deposits (this may be disputed, see below), tissue atrophy, glucose hypometabolism, and cognitive decline by many years (Walsh and Selkoe, 2020). The apolipoprotein E4 (ApoE4) gene is expressed in more than $50 \%$ of $\mathrm{AD}$ patients, and is the most common AD genetic risk factor (Safieh et al., 2019). ApoE4 increases $A \beta$ production via its effect on $\gamma$-secretase activity, impairing lysosomal $A \beta$ degradation, and possessing impaired ability to transport $\mathrm{A} \beta$ across the BBB (Safieh et al., 2019).

In contrast to the $A H$, some studies suggest $A \beta$ is not the sole cause of $\mathrm{AD}$. Tau correlates more strongly than amyloid with cognitive impairment (Bejanin et al., 2017). While genetic factors for late-onset $\mathrm{AD}$ include those affecting $\mathrm{A} \beta$, others affect pathways related to tau binding proteins or alternate mechanisms (Kunkle et al., 2019). Subtle cognitive deficits may occur prior to or coincident with early amyloid build-up, suggesting AD may be initiated prior to amyloid pathology (Thomas et al., 2020). A counterargument in support of the $\mathrm{AH}$ is $\mathrm{A} \beta$ deposition may be an early event that initiates $\mathrm{AD}$ pathology and cognitive decline (Selkoe and Hardy, 2016). A $\beta$ build-up may not be expected to correlate with cognitive performance in this interpretation.

Active immunization with $\mathrm{A} \beta$ prevents amyloid deposition in mouse models, although effectiveness of treatments is diminished in mice with extensive amyloid deposition (Das et al., 2001). Immunization causes mice to generate antibodies through $A \beta$ exposure, enabling microglial to bind to and eliminate plaques. This therapy translated to humans reduced amyloid burden, however cognitive improvement was absent. Some patients demonstrated signs of severe dementia despite clearance of amyloid deposits (Holmes et al., 2008; Gallardo and Holtzman, 2017). Furthermore, 6\% of immunized patients developed meningoencephalitis (Gilman et al., 2005).

Amyloid treatments may not be successful is amyloid removal via therapy causes amyloid to deposit on vessel walls, inducing hemorrhage and trapping toxic peptides within tissue in mice and humans (Wilcock et al., 2004; Patton et al., 2006). Another possibility is soluble $A \beta$ surrounds the plaques and prevent the administered antibody from reaching the plaques in sufficient concentration (Demattos et al., 2012).

Failures have also occurred with passive immunotherapies where an externally produced antibody is administered, as opposed to one internally generated through immunization. For example, bapineuzumab failed to reduce amyloid load or phosphorylated tau in cerebrospinal fluid (CSF) in phase 3 trials (Vandenberghe et al., 2016).

Several factors may contribute to failure of AH-based drugs beyond a simple assumption the $\mathrm{AH}$ is flawed. Amyloid deposition occurs many years prior to cognitive decline (Jack et al., 2013). Therapies may be administered by the time the effects of neuronal loss and tissue atrophy are irrevocable. This may be overcome in clinical trials using biomarkers to select patients with mild dementia attributable to early AD (Frisoni and Blennow, 2013). Selection of appropriate biomarkers to detect early $\mathrm{AD}$ or monitor progress is complex since numerous biomarkers are applicable, such as positron emission tomography (PET) amyloid imaging, fluorodeoxyglucose PET to detect 
hypometabolism, CSF tau, MRI to detect brain atrophy, and CSF YKL-40 (an indicator of activated microglia) (Zetterberg and Bendlin, 2020).

In humans abnormally phosphorylated tau occurs in nerve cells or their processes prior to 30 years of age, and before extracellular amyloid plaques deposits (Braak and Del Tredici, 2011). Phosphorylated tau could spread to other brain regions, such as the brainstem and entorhinal cortex, contributing to $\mathrm{AD}$ (Jack et al., 2013). This appears to support the Tau Hypothesis (tau drives AD progression, see Section The Tau Hypothesis: Tau as a Driver of Neurodegeneration), suggesting that targeting amyloid may be ineffective if abnormal tau is not concurrently eliminated. An alternative interpretation is since tauopathy occurs in asymptomatic individuals, tauopathy may be an element of aging but not AD specifically (Jack et al., 2013). Tauopathy and $A \beta$ pathology may occur independently, with tauopathy preceding $A \beta$ deposition. $A \beta$ accelerates tauopathy, eventually leading to NFTs in the neocortex (Musiek and Holtzman, 2012; Jack et al., 2013). This potentially occurs in mice, where breeding APP-transgenic with tau-transgenic mice increases tau deposition, but does not alter A $\beta$ (Lewis et al., 2001; Selkoe and Hardy, 2016).

$\mathrm{A} \beta$ antibodies may not clear soluble oligomers, which are believed to more significantly influence synapse loss and cognition compared to plaques. Plaques serve as "reservoirs" of soluble and toxic $A \beta$, without being as directly toxic themselves (Koffie et al., 2009; Walsh and Selkoe, 2020). This characteristic may partially explain why some individuals with plaques do not appear to suffer cognitive consequences, since these cognitively normal individuals have a low ratio of soluble oligomer to plaque ratios (Walsh and Selkoe, 2020).

Challenges with drug therapies may not be due to $A \beta$ specifically, but drug design. $\gamma$-secretase inhibitors potentially may inhibit $A \beta$ accumulation by preventing cleavage at the $\gamma$-secretase site. Many $\gamma$-secretase inhibitors have been identified, however they are not specific for cleavage of APP. They also inhibit processing of Notch and other proteins involved in development, cell adhesion, hematopoiesis, and contacts between cells (Evin et al., 2006). This may induce serious side effects. Treatment with a $\gamma$-secretase inhibitor, semagacestat, was associated with cognitive decline and skin cancer as a side-effect. This skin cancer was potentially attributable to blocking Notch1 cleavage (Extance, 2010).

\section{The Tau Hypothesis: Tau as a Driver of Neurodegeneration}

In the Tau Hypothesis, tau (a microtubule-associated protein) replicates and spreads between cells. This causes neurodegeneration through mechanisms such as synaptic impairment and changes to mitochondrial structure and function through interactions between tau and actin (DuBoff et al., 2012; Kametani and Hasegawa, 2018). Phosphorylated tau induces cognitive deficits through decreasing the number of synapses and triggering cell death (Di et al., 2016).

In a PET study, the intensity of tau signal, but not $A \beta$, predicted the rate of tissue atrophy at early clinical $\mathrm{AD}$ stages
(La Joie et al., 2020). Tau pathology could appear in healthy older adults without amyloid (Harrison et al., 2019), and may be present in brains of individuals with mild dementia absent A $\beta$ pathology (de Paula et al., 2009). Extensive tau pathology is believed to occur as a result of $A \beta$ accumulation, as demonstrated in neuronal cell cultures, mouse models, and genetic studies (Selkoe, 2011; Choi et al., 2014). This renders it unlikely to initiate AD by itself, although tau abnormalities may begin in childhood (Braak and Del Tredici, 2011).

Drugs targeting tau phosphorylation or aggregation have not successfully translated from mice to humans. For example, glycogen synthase kinase-3 (GSK3 $\beta$ ) is a serine/threonine kinase facilitating tau hyperphosphorylation. In a mouse model overexpressing human mutant APP and tau, a GSK3 $\beta$ inhibitor affected multiple targets including reduced tau phosphorylation and amyloid deposition. This potentially protected against neuronal death and memory deficits through inhibiting the intrinsic mitochondrial signaling pathway to reduce cellular damage (Serenó et al., 2009). Clinical benefits were not obtained when a GSK-3 inhibitor, Tideglusib, was tested in clinical trials (Lovestone et al., 2015). Similar to $A \beta$ therapies, possibly clinical trials of GSK-3 inhibitors are conducted at too late a disease stage to be effective (Hernandez et al., 2013).

\section{Inflammation}

In early $\mathrm{AD}$, scavenger receptors (SRs) on microglia promote A $\beta$ clearance (Wang et al., 2015). As amyloid builds, continual microglial interaction with $A \beta$ via additional receptors (such as CD36) cause release of pro-inflammatory cytokines, leading to neuronal damage (Wang et al., 2015).

$\mathrm{AD}$ brains demonstrate chronic inflammation, with microglia displaying increased activity in AD patients (Liu et al., 2019). Amoeboid microglia indicating an activated inflammatory state are associated with $\mathrm{A} \beta$, with microglial activation occurring following amyloidosis and neuronal injury, and possibly promoting tau accumulation (Suárez-Calvet et al., 2016; Hemonnot et al., 2019). Microglia may damage neurons directly as evident in axonal damage co-localizing with microglial cells in vitro (Park et al., 2018).

Inflammation may be a causative factor in AD. Epidemiology studies indicate a possible protective effective of antiinflammatories (Andersen et al., 1995). Ibuprofen reduced amyloid deposition, cognitive decline, and inflammatory markers in transgenic mice (Lim et al., 2000; Van Dam et al., 2010). In wild type mice, a systemic prenatal immune challenge caused $\mathrm{AD}$-like pathology, with elevation in inflammatory cytokines, increased hippocampal APP, and altered tau phosphorylation (Krstic et al., 2012).

A genetic risk associated with plaque clearance in $\mathrm{AD}$ is CD33 expression, a myeloid cell receptor expressed by microglia activated by glycoproteins and glycolipids and displayed on plaques (Hollingworth et al., 2011; Naj et al., 2011; Zhao, 2019). $\mathrm{CD} 33$ expression is elevated in $\mathrm{AD}$, and deletion of the gene in the APP/PS1 mouse model reduces insoluble $A \beta$ and plaque levels (Griciuc et al., 2013). The activated receptor recruits proteins such as SHP phosphatases that inhibit phagocytosis (Zhao, 2019). CD33 inhibitors are an area of drug development research, 
although translation from mice to humans is challenging due to species differences in protein domain structure (Biber et al., 2019). Another transmembrane receptor found in microglia and neurons associated with $\mathrm{AD}$ is triggering receptor expressed by myeloid cells 2 (TREM2), which is involved in phagocytosis and preventing inflammatory mediator production (Doens and Fernández, 2014). TREM2 mutation reduces microglial clustering around plaques in mice and humans, resulting in enhanced neuritic dystrophy (Carmona et al., 2018).

Scheiblich et al., 2020 use a "Wave Model" to describe inflammation progression in AD. Pattern recognition receptors (PRRs) on microglia detect $A \beta$, followed by tau and other misfolded proteins. This activates proinflammatory pathways and toxic cytokines contributing to $\mathrm{AD}$ such as $\mathrm{TNF} \alpha$, IFN $\gamma, \mathrm{ROS}$, and IL (interleukin)-1 $\beta, 4,6,9,12,23$ (Mandrekar-Colucci and Landreth, 2010; Scheiblich et al., 2020). TNF $\alpha$ and IFN $\gamma$ reduce levels of insulin degrading enzyme, impairing degradation of $A \beta$, and also impair microglial phagocytosis of A $\beta$ (Mandrekar-Colucci and Landreth, 2010). The interleukins and $\mathrm{TNF} \alpha$ trigger neuronal signaling leading to phosphatase inactivation and kinase activation, causing tau hyperphosphorylation, aggregation into toxic forms, and ultimately neuronal loss and dysfunction (Scheiblich et al., 2020). This neuronal loss is associated with altered concentrations of neurotransmitters, and enhanced astroglial and microglial proliferation (Scheiblich et al., 2020). An element of the inflammatory response is the NLRP3 inflammasome, which activates caspase- 1 and ASC specks, which then bind to $A \beta$ and induce its aggregation (Venegas et al., 2017; Scheiblich et al., 2020). The ASC specks may be absorbed by myeloid cells, resulting in sustained immunoactivity (Venegas et al., 2017).

Inflammation exerts effects on blood vessels through perivascular cells. In healthy tissue, perivascular macrophages (PVMs, macrophages contacting a vessel or within a cell thickness of a vessel) limit vessel permeability through maintenance of endothelial cell tight junctions, phagocytose pathogens, restrict inflammation, and control leukocyte movement across the vasculature (Lapenna et al., 2018). PVMs have a protective role by scavenging amyloid, as seen in a study in TgCRND8 mice where depletion of PVMs enhanced CAA load (Hawkes and McLaurin, 2009; Lapenna et al., 2018). However, $\mathrm{A} \beta$ stimulates PVM ROS release, contributing to cerebrovascular oxidative stress and vascular dysfunction through smooth muscle contraction (Lapenna et al., 2018). In wild-type mice where $A \beta_{40}$ was infused through the carotid artery, PVM depletion restores the ability of the vasculature to increase blood flow in response to functional stimulation or vasodilators (Park et al., 2017). The source of PVM-induced vascular dysfunction is $A \beta$ in bloodstream that crosses the vascular wall, binding to CD36 (cell surface receptor) on PVMs and leading to Nox2 ROS production (Park et al., 2017; Lapenna et al., 2018).

\section{Additional Factors Influencing Alzheimer's Progression The Female Gender}

Most $\mathrm{AD}$ patients are female $(\sim 2 / 3)$, with females exhibiting reduced glucose metabolism in comparison with males (Mosconi et al., 2018). Menopause is believed to increase AD risk. Estrogen has protective effects such as reducing neuronal vulnerability to apoptosis through expression of anti-apoptotic proteins, and reducing oxidative stress through acting on mitochondria (Henderson and Brinton, 2010). Studies in 3xTg AD mice demonstrated ovariectomy reduced memory performance and increased A $\beta$ accumulation (Carroll et al., 2007). Hormone replacement therapy has therefore been proposed to reduce $\mathrm{AD}$ risk. If administered prior to or at menopause in humans, glucose metabolism is preserved in regions susceptible to $\mathrm{AD}$ and prevents cognitive decline, potentially through increasing blood flow (Maki and Resnick, 2000; Brinton, 2008; Rasgon et al., 2014; Scheyer et al., 2018). This therapy is ineffective in postmenopausal women and is associated with an increased risk of AD (Savolainen-Peltonen et al., 2019). Long-term estrogen depletion may render an individual non-responsive to therapy due to decreased hippocampal estrogen-receptor- $\alpha$ (Scheyer et al., 2018). Alternatively, damage to mitochondria may cause estrogen to increase neurological damage (Brinton, 2008; Scheyer et al., 2018).

\section{Abnormal Protein Disposal Mechanisms}

Late onset $\mathrm{AD}$ is characterized by impaired $\mathrm{A} \beta$ clearance (Mawuenyega et al., 2010). Most $A \beta$ is cleared through the $\mathrm{BBB}$, although cerebrospinal fluid (CSF) contributes to A $\beta$ clearance (Ramanathan et al., 2015). Subarachnoid CSF enters brain parenchyma through paravascular spaces around penetrating arteries. It mixes with interstitial fluid (ISF) in the brain interstitium, facilitated by aquaporin 4 (AQP4, a water channel protein) in astrocytes. This CSF-ISF mixture, via bulk flow or diffusion, travels through the tissue and is eliminated along paravascular spaces surrounding veins (Iliff et al., 2012; Reeves et al., 2020). The ISF bulk flow between these two pathways (i.e., para-arterial and paravenous routes) clears $A \beta$ from the brain. Since ISF flow is mediated by AQP4 in cell membranes of astroglia, and due to its similarity to the lymphatic system, this pathway is termed the "glymphatic system" (Iliff et al., 2012). Ultimately, solutes (such as A $\beta$ ) and ISF diffuse to subarachnoid CSF, enter the bloodstream, or travel along the venular walls to the lymphatic system (Iliff et al., 2012). The importance of the glymphatic pathway is seen in the study by Xu et al. (2015), where AQP4 deletion in 12month old APP/PS1 mice increased $A \beta$ and cerebral amyloid angiopathy (CAA), as well as increased atrophy of astrocytes and memory impairment.

This fluid movement is driven largely by cardiac-generated penetrating arterial pulsation. This was shown in a mouse study where reducing pulsatility through internal carotid artery ligation reduces arterial pulsation and CSF-ISF exchange (Iliff et al., 2013). In a mathematical model, it was demonstrated that decreasing heart rate (and consequently arterial pulsations) and increasing arterial stiffness led to elevated brain $\mathrm{A} \beta$ deposition (Kyrtsos and Baras, 2015).

Plaque build-up along vessels contributes to reduced amyloid clearance. CAA increases arterial wall stiffness, reducing pulsatility and ISF movement (Reeves et al., 2020). A $\beta$ deposition may also reduce space around arteries for fluid flow, increasing accumulation in tissue (Reeves et al., 2020). 
Studies do not generally correlate vascular changes, such as microvessel density or tortuosity, with glymphatic clearance. Peng et al. (2016) found suppression of glymphatic transport in both aged (12-13 months) and young (3-4 months) APP/PS1 mice prior to significant $\mathrm{A} \beta$ deposits or CAA, when extensive vascular loss begins to occur. Since vessel density in APP/PS1 mice at 18-months does not differ between transgenic and agematched controls (Hooijmans et al., 2007), it is reasonable to assume that the impaired glymphatic clearance at 3-13 months is not attributable to vessel loss. Mice models do experience changes in microvascular morphology at early time points prior to vascular loss (Durrant et al., 2020). It is conceivable that these morphological changes reflect dysfunctional vasculature, which could contribute to impaired $\mathrm{A} \beta$ clearance.

Aging contributes to impaired glymphatic clearance, since older mice experience a drop in penetrating arterial wall pulsatility, with a corresponding reduced ability to clear $A \beta$ injected into brain tissue (Kress et al., 2014). In humans, loss of vascular compliance is associated with $\mathrm{A} \beta$ deposition, possibly due to structural changes in elastin (Fonck et al., 2009). Kress et al. (2014) propose that reduced compliance with aging is a contributor to reduced pulsatility. Alternatively, since astrocytes contact arteries via their endfeet, changes to astrocytes may occur during reactive astrogliosis that could affect arterial pulsatility (Kress et al., 2014).

Extracellular proteins may be degraded via cellular secretion of protein-degrading enzymes (Tarasoff-Conway et al., 2015). The two main routes of $\mathrm{A} \beta$ clearance in cells is through the ubiquitin-proteasome and autophagy-lysosome pathways (Perez et al., 2014). Due to reduced proteasome activity with aging, A $\beta$ accumulates intracellularly, causing excessive lysosome activity that prevents cells from increasing protein degradation rate in response to stress (Ding et al., 2003; Perez et al., 2014).

\section{Environmental Risk Factors}

Nitrogen oxides and tobacco smoke are associated with greater dementia risk (Killin et al., 2016). Higher lead concentrations lead to an increased likelihood for $\mathrm{AD}$, possibly attributable to astrocyte activation and alterations to tight junction proteins that induce BBB dysfunction (Killin et al., 2016).

While air particles may enter the body through lungs and blood stream, they commonly enter through the olfactory bulbs. A study (Calderón-Garcidueñas et al., 2010) of Mexico City residents found olfactory bulb inflammation and $A \beta_{42}$ accumulation in vessels, neurons, and glia. A significant contributor to $A \beta_{42}$ accumulation is ultrafine nanoparticles in the environment that promote oligomer formation/fibrillation (Linse et al., 2007; Calderón-Garcidueñas et al., 2010). They are dangerous because they are not bound to membranes, enabling access to organelles, and proteins (Calderón-Garcidueñas et al., 2010).

\section{VASCULATURE IN ALZHEIMER'S DISEASE}

Vessel damage in $\mathrm{AD}$ is present in vessels of all sizes. This includes flow reductions in large arteries in the Circle of Willis (Krucker et al., 2004) and penetrating arterioles displaying a twisted morphology (Dorr et al., 2012). Section Vasculature in Alzheimer's Disease below focuses on capillaries and microvasculature since capillary compression is a significant contributor to reduced $\mathrm{CBF}$, and $\mathrm{BBB}$ damage may initiate or precede dementia (Cruz Hernández et al., 2019; Nation et al., 2019; Montagne et al., 2020).

\section{The Aging Vasculature and Alzheimer's}

Reduced capillary density with aging is attributed to diminished levels of angiogenic growth factors (such as VEGF), an imbalance between production of angiogenic and anti-angiogenic growth factors, and reduction of nitric oxide release and impaired vasodilation (Rivard et al., 1999; Ahluwalia et al., 2013; Ambrose, 2017).

Ambrose (2012) proposed the Neuroangiogenesis Hypothesis, wherein a decline in growth factors and angiogenic cytokines leads to a reduction in vessel density and cognition. Restoration of vessel density through administration of growth factors, such as VEGF, is proposed as a treatment to prevent development of AD symptoms (see Section Discussion).

In addition to vessel loss, aging is linked to increased capillary tortuosity and a thickened basement membrane (Østergaard et al., 2015). Pericytes are lost or become dysfunctional, causing $\mathrm{BBB}$ dysfunction and impaired flow regulation that decreases oxygen concentration in tissue (Kisler et al., 2017; Berthiaume et al., 2018). Aging may cause downregulation of the endothelial low density lipoprotein receptor 1 (LRP1) due to activation of protein kinase $\mathrm{C} \alpha$ (Silverberg et al., 2010). LRP1 eliminates A $\beta$ proteins through the $\mathrm{BBB}$, and its reduced concentration causes amyloid build-up.

Decreased neprilysin (the main $A \beta$ degrading enzyme) in cells with aging leads to impaired amyloid clearance ability (Sasaguri et al., 2017). A $\beta$ peptides (in particular the more soluble $A \beta_{40}$ ) therefore comprise a large proportion of atherosclerotic plaques (Kokjohn et al., 2011). Atherosclerosis develops prior to brain $\mathrm{A} \beta$ deposition and neural dysfunction in APP23 mice, indicating a possible contribution or connection between atherosclerosis and dementia (Tibolla et al., 2010). Most AD individuals display atherosclerosis in the Circle of Willis, with arteries to which blood is delivered by the Circle of Willis displaying decreased blood flow and increased pulsatility index (Gupta and Iadecola, 2015). Decreased blood flow causes tissue hypoxia and elevated $\mathrm{A} \beta$ production through increased $\beta$-secretase activity (Gupta and Iadecola, 2015). Increased arterial stiffening, as indicated by the elevated pulsatility index, transfers excessive pulsatile energy to capillaries (Wåhlin and Nyberg, 2019). This energy transfer leads to pericyte injury and BBB breakdown in the hippocampus, impairing memory function (Wåhlin and Nyberg, 2019).

Atherosclerosis and $\mathrm{AD}$ are associated with blood flow reductions, vessel occlusions, and arterial wall thickening. Differences exist between the conditions. Atherosclerosis is associated with cholesterol-rich arterial wall deposits, while AD is characterized by plaques and tangles leading to neuron loss. Deposition of A $\beta$ plaques on blood vessels, as in CAA, further reduces blood flow. Whereas in atherosclerosis, many deposits are on major arteries (including outside the brain, such as the aorta), in $\mathrm{AD}$ deposits are located on intracerebral arterial 
vasculature (Lathe et al., 2014), such as penetrating arterioles in TgCRND8 mice (Dorr et al., 2012) and capillaries in a human study (Hecht et al., 2018). Capillary deposits correspond to impaired blood flow in the APP23 mouse model (Thal et al., 2009). In humans, these deposits are associated with tissue microinfarcts in the hippocampus and cognitive decline (Hecht et al., 2018). In atherosclerosis, macrophages laden with cholesterol accumulate in vessel walls, diminishing blood flow to multiple tissues. Rupture of these plaques may lead to stroke or myocardial infarction (Lathe et al., 2014). While atherosclerosis and $\mathrm{AD}$ may share similarities, and atherosclerosis is a risk factor for $\mathrm{AD}$, causes of reduced blood flow and tissue damage differ.

Vascular risk factors are prominent in aged populations. This may be due to aging-induced inflammation and cytokine release, leading to endothelial dysfunction and arterial stiffening (Sun, 2015). Hypertension is associated with microvascular abnormalities such as endothelial swelling and reduced capillary density (Boudier, 1999; Østergaard et al., 2015). This microvascular deficiency in hypertension is potentially aggravated by a deficiency in circulating insulin-like growth factor 1 (IGF-1) due to aging (Tarantini et al., 2016). However, a meta-analysis from our lab (ZP Feng) was not able to conclusively determine whether there was an increase or decrease in IGF-1 levels in $\mathrm{AD}$ subjects, indicating that IGF-1 may not be the source of microvascular dysfunction in $\mathrm{AD}$ (Ostrowski et al., 2016).

\section{Cerebral Amyloid Angiopathy and the Vascular Hypothesis}

In rodents, reductions in $\mathrm{CBF}$ increase $\mathrm{A} \beta$ deposition and induce memory deficits (Wang et al., 2016). Reduced blood flow may increase amyloid pathology through activation of $\beta / \gamma$-secretases that induces APP cleavage (Cai et al., 2017), through failure of A $\beta$ drainage from the brain (Weller et al., 2008, 2009), or increased rate of tau phosphorylation (Koike et al., 2010). A $\beta$ may deposit on artery walls or leptomeningeal vessels, and to a lesser extent capillaries (Preston et al., 2003; Thal et al., 2008; Weller et al., 2009). This is termed cerebral amyloid angiopathy (CAA), and is associated with vessel bleeding (Thal et al., 2009; Yates et al., 2014).

There are two main CAA subtypes: Type 1 occurs in cortical capillary walls, arterioles, leptomeningeal and cortical arteries, and venules/veins, whereas Type 2 does not occur in capillaries (Thal et al., 2002). Capillary CAA is regarded as a distinct CAA type, occurring in populations with a high ApoE4 allele frequency and correlating with AD pathology severity (Kövari et al., 2013). In arteries and veins, there is a higher ratio of $A \beta_{40}: A \beta_{42}$ compared to senile plaques, with a similar ratio in capillaries compared to senile plaques (Thal et al., 2008). Potentially, this higher ratio of $A \beta_{40}$ is due its solubility, enabling it move within perivascular drainage pathways and accumulate in vessel walls (Greenberg et al., 2020). CAA begins as small A $\beta$ deposits on basement membranes of arteries, eventually depositing in the muscle cell layer (Thal et al., 2008). In severe cases, the smooth muscle cell layer deteriorates, and capillaries become occluded in mice and humans, reducing cerebral blood flow (Thal et al., 2008, 2009). CAA in mouse models is described in more detail by Klohs et al. (2014).

Understanding mechanisms by which CAA develops, or plaques deposit on the vasculature, is important in developing AD immunotherapies. Boche et al. (2008) analyzed brains of $\mathrm{AD}$ patients that died following immunization against $A \beta_{42}$. Compared to controls, immunized individuals demonstrated more frequent cortical microvascular lesions and microhemorrhages, with significantly more $A \beta_{42}$ deposited on cortical blood vessels and the leptomeninges. Solubilization of $A \beta_{42}$ via immunotherapies may overwhelm perivascular clearance pathways, leading to increased CAA (Greenberg et al., 2020).

Despite similarities between CAA and AD, these diseases are not identical. At least $60 \%$ of individuals above 80 years old are afflicted with CAA, indicating CAA is not restricted to $\mathrm{AD}$ (Thal et al., 2008). CAA and AD share additional biomarkers such as cortical thinning and atrophy, cerebrovascular dysfunction, and tau deposition (Greenberg et al., 2020). Advanced CAA is associated with higher levels of cognitive impairment in $\mathrm{AD}$ (Greenberg et al., 2020), suggesting a link between aberrant vascular changes induced by CAA and AD development.

Linkages between vascular risk factors and dementia has led $\mathrm{AD}$ to be described as a vascular disorder. de la Torre and Mussivand (1993) proposed a hypothetical model where capillaries in brain aging undergo degeneration in response to amyloid deposits. This disturbs blood flow and causes proliferating glia produce APP (de la Torre and Mussivand, 1993; de la Torre, 1994). Factors contributing to brain dysfunction from impaired blood flow include decreased production of energy molecules such as ATP and failure to transmit signals between neurons.

Vascular-based hypotheses have implications for therapeutic targets. Anti-inflammatories, statins, and hypertension drugs are possible alternatives to targeting $A \beta$ (Townsend and Praticò, 2005; Rius-Pérez et al., 2018). Anti-inflammatories reduce A $\beta$ deposition and inflammation in mouse models (Yan et al., 2003; Heneka et al., 2005), with long-term administration of nonsteroidal anti-inflammatory drugs lowering AD risk by $30-60 \%$ (Herrup, 2010).

\section{Vascular Dysfunction and Morphology}

Examples of abnormal capillary features include pits in vessel walls, loss of vascular innervation by neurons, and tortuous shaped vessels (Scheibel et al., 1989; de la Torre, 1994). An elevated number of non-perfused "string" vessels are present in $\mathrm{AD}$, possibly explaining reduced flow despite occasional similar densities of capillaries between $\mathrm{AD}$ and healthy aging (Brown and Thore, 2011; Hunter et al., 2012).

Studies in mice support a role for $A \beta$ in reducing $C B F$. Administration of $A \beta_{40}$ to cortex in wild type mice reduces cortical blood flow and diminishes $\mathrm{CBF}$ increases induced by vasodilators, probably through generation of ROS by $\mathrm{A} \beta_{40}$ (Niwa et al., 2000). Mice over-expressing superoxide scavenging enzyme superoxide dismutase-1 (SOD1), or whose cortex was superfused with SOD, reverse vascular deficits induced by amyloid (Iadecola 
et al., 1999; Niwa et al., 2000). A $\beta_{42}$ did not similarly influence resting $\mathrm{CBF}$ or endothelial response to vasodilators, suggesting that $A \beta_{40}$ may have a more significant vascular effect.

A potential mechanism underlying $A \beta_{40}$ - and ROS-induced vascular dysfunction was elucidated in Park et al. (2014). A $\beta$ activates innate immunity receptors on endothelial cells, leading to Nox 2 production of superoxide. This superoxide reacts with nitric oxide (NO) produced in endothelial cells to produce peroxynitrite $(\mathrm{PN})$. PN damages DNA, leading to a series of reactions that activate calcium-permeable ion channel TRPM2. This permits excessive $\mathrm{Ca}^{2+}$ entry into the cell, inducing the observed endothelial dysfunction such as vessel constriction, reduced blood flow, and vascular hyperpermeability. The potential of TRPM2 as a therapeutic target is evaluated further in the Section Discussion.

Endothelial dysfunction does not require plaque accumulation, only exposure to $A \beta$. This may explain blood flow reductions and observed microvascular abnormalities. Mice overexpressing APP and APP-derived A $\beta$ peptides (Tg2123 and Tg2576) demonstrate blood flow reductions prior to plaque deposition, with the Tg2576 mouseline that possesses higher levels of $A \beta$ demonstrating widespread reductions in CBF (Niwa et al., 2002). This may similarly occur in humans, as early $\mathrm{CBF}$ reductions occur prior to neuropathological changes and cerebrovascular responses to functional activation are impaired individuals at high AD risk (Smith et al., 1999; Niwa et al., 2000).

This suggests multiple phases of vascular dysfunction: one occurring prior to vessel loss, the second attributable to vascular destruction and regression. In humans, CBF deficits are present in the pre-dementia phase of $\mathrm{AD}$, while blood volume changes indicative of vascular structural alterations are detected at the $\mathrm{AD}$ stage (Lacalle-Aurioles et al., 2014).

In the APP23 mouse model, at young ages prior to plaques, small deposits containing $A \beta$ are found primarily attached to capillaries (Meyer et al., 2008). These deposits, associated with distorted microvessels, are proposed to alter local blood flow. This is believed to trigger increased amyloid production, ultimately resulting in vascular degeneration at older ages (Meyer et al., 2008). Since these deposits contain $A \beta_{42}$, this suggests a role for $A \beta_{42}$ in instigating vascular dysfunction, in addition to $A \beta_{40}$ discussed above. Similar capillary deposits have been observed in humans, lending support to the findings in mice (Miyakawa, 1997).

Studies in the APP/PS1 mouse model suggest capillary dysfunction prior to vessel loss. Despite similar cortical capillary length density in transgenic compared to wild-type mice at 18 months, cortical oxygen availability was reduced in the transgenic mice as indicated by reduced capillary blood flow and elevated capillary transit time heterogeneity at rest (Gutiérrez-Jiménez et al., 2018). This was attributed to factors such as abnormal cholinergic innervation of blood vessels, arterial contraction, or increased vessel tortuosity (Gutiérrez-Jiménez et al., 2018). Compared to wild types, APP/PS1 transgenic mice demonstrate increased blood flow and capillary flow homogenization in response to functional activation (Gutiérrez-Jiménez et al., 2018). The authors note in contrast to humans and other mouse models that display pericyte degeneration, pericyte numbers are not changed in the APP/PS1 model at 18-months. Vasodilation involving pericyte signaling, such as pericyte relaxation at the capillary wall (Hall et al., 2014), may be preserved, explaining the increased flow in response to functional activation (GutiérrezJiménez et al., 2018).

In contrast to early blood flow reductions, some researchers record hyperperfusion in brain regions vulnerable to $\mathrm{AD}$ pathology in young, high-risk subjects (Fleisher et al., 2009; Bangen et al., 2012; Østergaard et al., 2013). This may be attributable to early capillary dysfunction that leads to reduced oxygen extraction by tissue from the microvasculature, causing a compensatory increase in CBF (Østergaard et al., 2013, 2015).

\section{Angiogenesis and Alzheimer's Pathology}

Vagnucci and Li (2003) proposed the "Angiogenesis Hypothesis." They observed drugs which reduce AD risk, such as statins, may possess anti-angiogenic properties. In addition, microvessel density is increased in AD (Perlmutter et al., 1990). In the Angiogenesis Hypothesis, neovascularization occurs in response to reduced blood flow and vascular injury due to inflammation. Pre-amyloid deposits on capillaries generate reactive oxygen species. This causes intravascular accumulation of thrombin and endothelial release of APP.

Studies in the Tg2576 mouse model suggest amyloid could trigger angiogenesis, causing BBB leakage and hypervascularity (Biron et al., 2011). This model demonstrates BBB disruption at 4-months, prior to plaque appearance (Ujiie et al., 2003). Aged (18-24 month old) Tg2576 mice displayed increased cortical microvessel density, similar to humans, corresponding with the degree of tight junction disruption (Biron et al., 2011). The hypervascularity observed in Tg2576 mice was reversed through immunization with $\mathrm{A} \beta$ (Biron et al., 2013). In mice, the anti-angiogenic bexarotene (an anti-cancer agent) clears $A \beta$ and restores memory function (Cramer et al., 2012; Jefferies et al., 2013). However, angiogenic activation of endothelial cells occurs following cognitive decline in the APP23 mouse model (Schultheiss et al., 2006), suggesting angiogenesis may not initiate AD.

Some studies contradict the angiogenic properties of amyloid. Most human $\mathrm{AD}$ specimens display reduced vessel density (Brown and Thore, 2011). There is reduction in capillary density in white matter in 10-month old Tg2576 mice (Zhang et al., 2019), with $A \beta$ inhibiting angiogenesis (Paris et al., 2004c) and potentially reducing vessel density in cortex and hippocampus (Paris et al., 2004a).

There are explanations for these discrepancies. Plaque deposits create "holes" in the vascular bed, while vessels proliferate around these holes (Meyer et al., 2008). An overall measure of vessel density may indicate loss of vessels due to holes, without accounting for the increase in vessels surrounding holes. A simultaneous loss and growth of vessels in human AD specimens has been observed (Desai et al., 2009). Despite the presence of angiogenic vessels in all brain regions, only the hippocampus demonstrated an increase in total capillary density (angiogenic plus non-angiogenic vessels) (Desai et al., 2009). Vessels may reside in a permanent angiogenic state, constantly growing and regressing in human studies (Desai 
et al., 2009), resulting in no net change or even a loss of vessel density. See Figure $\mathbf{1}$ for a diagram of vasculature in $\mathrm{AD}$ and healthy conditions.

Capillary density in $\mathrm{AD}$ models may be dependent on age or brain region. In the Tg2576 mouse model, at 5-months old cortical microvascular density is elevated, while at 27months density is diminished (Giuliani et al., 2019). In the TgCRND8 mouse line, there is increased microvessel density at postnatal day 7 (Durrant et al., 2020), while in adulthood vessel density is reduced below controls in cortex (Religa et al., 2013). This elevated microvessel density at P7 was accompanied by increased microvessel tortuosity. This may indicate "pathological angiogenesis," or formation of dysfunctional blood vessels. In the same model (TgCRND8) at 6-months, a decrease in density was found in cortex, while it was increased in hippocampus relative to non-transgenic mice, suggesting a heterogenous angiogenic response depending on brain region (Maliszewska-Cyna et al., 2020).

The reduced vessel density at older ages might be attributable to the aging process and reduced expression of angiogenic growth factors. In brains without $\mathrm{AD}$, decline in growth factors with aging, such as VEGF, fibroblast growth factor (FGF-1 and FGF-2), and angiopoietin, yield slow recovery in tissue wound injuries due to reduced angiogenic capabilities (Ambrose, 2017), or display reduced angiogenesis in response to hypoxia (Benderro and Lamanna, 2011). In a human study, Huang et al. (2013) found significant reduction in serum VEGF relative to both amnestic mild cognitive impairment and control (healthy) individuals. Transforming growth factor $\beta 1$ (TGF$\beta 1$ ) (an angiogenic growth factor) serum concentration was reduced in $\mathrm{AD}$, with the reduction in VEGF and TGF- $\beta 1$ levels correlating with cognitive impairment severity (Huang et al., 2013). Huang et al. (2013) hypothesized this indicates reduction in angiogenic growth factors contribute to cognitive impairment. Since VEGF deposits with $A \beta$, it is possible that $A \beta$ accumulation decreases available VEGF. This leads to reduced growth factor concentration available for angiogenesis, diminishing the number of blood vessels and inducing hypoperfusion (Huang et al., 2013). TGF- $\beta 1$ reduction in AD patients has been recorded in another study, De Servi et al. (2002) verifying the findings of Huang et al. However, Kim and Kim (2012) recorded AD patients as possessing higher serum VEGF, while angiogenin (protein that stimulates angiogenesis) is reduced. Luppi et al. (2009) recorded significantly reduced VEGF, TGF- $\beta 1$, and IGF- 1 secreted by immune cells in $\mathrm{AD}$ patients. Together, these findings provide a potential explanation for reduced vessel density observed in AD.

\section{Blood Brain Barrier Leakage and Disruption}

The BBB is formed through tight junctions between endothelial cells, and regulates movement of ions and molecules between blood vessels and brain tissue. The BBB consists of multiple cell types in addition to endothelial cells, which together comprise the "Neurovascular Unit" (NVU). The cells types of the NVU include endothelial cells, pericytes, smooth muscle cells (arterial and venous), astrocytes, microglia, oligodendrocytes, and neurons (Sweeney et al., 2019).

This protects neural tissue from pathogens or toxins. $\mathrm{BBB}$ dysfunction due to brain injury is a risk factor for dementia, resulting in immune cell influx into tissue, perivascular inflammation, CBF alterations, and accumulation of molecules prone to aggregation (Abrahamson and Ikonomovic, 2020).

The BBB is a component of the Two-Hit Vascular Hypothesis (Sagare et al., 2012), where vasculature risk factors reduced blood flow or BBB dysfunction. Flow decreases may be induced by atherosclerosis (Gupta and Iadecola, 2015), while BBB damage could be caused by pericyte degeneration (Miners et al., 2018; Montagne et al., 2018; Wåhlin and Nyberg, 2019). These vascular risk factors and vascular damage are the "First Hit" which initiate $\mathrm{A} \beta$ deposition (the "Second Hit"). BBB dysfunction leads to neurotoxin accumulation and impaired $A \beta$ clearance through the BBB. Reduced blood flow due to vascular damage also leads to elevated $A \beta$ production. Together, accumulation of $A \beta$ and hypoxic conditions initiate neuronal dysfunction, degeneration, and loss, causing dementia (Sagare et al., 2012).

$\mathrm{BBB}$ damage has consequences in not clearing $\mathrm{A} \beta$ and enabling toxins to enter brain tissue. In addition to LRP1 reduction with aging (see Section the Aging Vasculature and Alzheimer's), Receptor for Advanced Glycation End Products (RAGE) on endothelial cells binds circulating $A \beta$ and transports it across the BBB (Deane et al., 2009). RAGE interaction with $\mathrm{A} \beta$ contributes to oxidative stress, reduced blood flow, and inflammation (Deane, 2012). BBB leakage causes plasma proteins such as albumin, fibrin, thrombin, and immune cells to enter tissue. These proteins and cells generate neuroinflammation and act on neurons and glia, damaging axons (Strickland, 2018; Klohs, 2019).

Since BBB impairment occurs prior to cognitive impairment or A $\beta$ deposition (Klohs, 2019; Nation et al., 2019), BBB repair is an early target in $\mathrm{AD}$. Due to the connection between neuronal damage, inflammation, and $\mathrm{BBB}$, drugs developed to treat stroke have potential for translation to $\mathrm{AD}$. $3 \mathrm{~K} 3 \mathrm{~A}-\mathrm{APC}$, a drug for treating ischemic stroke, protects $\mathrm{BBB}$ through inhibition of endothelial apoptosis (Lazic et al., 2019). In a mouse model of AD administered 3K3A-APC daily for 4 months, neuronal production of $\mathrm{A} \beta$ was blocked through inhibition of $\beta$-secretase, neuroinflammation suppressed, BBB repaired, and $\mathrm{CBF}$ responses to stimulation restored (Lazic et al., 2019). This indicates a role for drugs that simultaneously reduce $A \beta$ production, protect the vasculature, and suppress inflammation.

BBB leakage due to inflammation increases susceptibility to environmental pollutants. Tiny particles absorbed by alveoli circulate through the blood stream, where they may enter the brain, or trigger further inflammation (Peeples, 2020).

\section{Imaging of Microvascular Dysfunction}

One technique extensively applied to image the microvasculature in $\mathrm{AD}$ is 2-photon microscopy. 2-photon microscopy uses high intensity, long-wavelength laser light to excite fluorophores close to $1 \mathrm{~mm}$ deep into cortical tissue. The vasculature is typically imaged following a tail vein injection of a fluorescent 
dye. Following imaging, the vasculature is segmented for quantification of structural properties of the network (Steinman et al., 2017, 2019). Blood flow simulations are performed on the vascular segmentations by approximating vessels as tubes (pipes), and application of equations which relate structural properties of the tube (length and diameter) to its blood flow resistance (Schmid et al., 2017).

An example of the benefits of flow simulations is seen in the study by Cruz Hernández et al. (2019), where blood flow reductions were calculated in simulations on mouse and human cortical vasculature due to capillary stalling. Observed flow reductions were attributed to the interconnectivity of the capillary network, where blockage of a single vessel reduces flow in downstream vessels.

Red blood cell (RBC) velocity in individual capillaries may be measured with 2-photon microscopy (Kleinfeld et al., 1998). This was demonstrated by Bennett et al. (2018) in tau P301L transgenic mice. Similar to Cruz Hernández et al. (2019), a number of very small diameter capillaries ( $<4$ um diameter) contained leukocytes adhered to their walls, and flow that was restricted to plasma (i.e., RBCs were absent). These capillaries also demonstrated abnormal morphology, such as a spiral shape.

A metric of capillary network function is the variation in blood flow across the capillary network. In healthy tissue, there is a
A

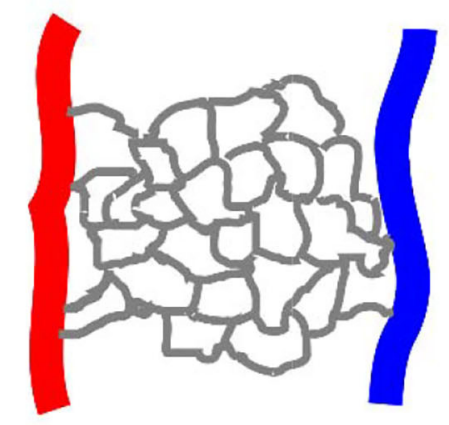

Healthy Brain Vasculature
B

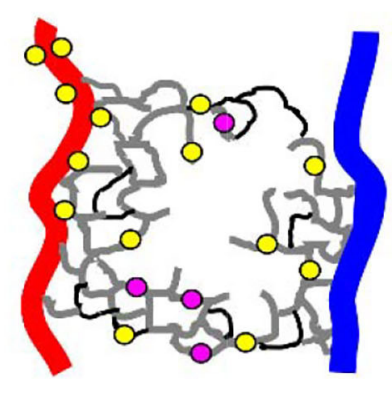

Alzheimer's Brain Vasculature

\section{Summary of Microvascular Changes}

- impaired blood flow and vascular reactivity

- reduced vessel density

- constriction of capillaries via amyloid deposits

- constriction of capillaries via pericytes

- capillary blockage via neutrophils

- blood brain barrier leakage

- string vessel formation

- aberrant angiogenes

- tissue atrophy

FIGURE 1 | Diagram of healthy and Alzheimer's brain vasculature. (A) Diagram of healthy brain vasculature. Penetrating arteries (red) and veins (b/ue) are connected via a capillary mesh (gray). (B) Diagram of Alzheimer's brain vasculature. Deposition of amyloid (yellow dots) in the vascular bed causes vascular dysfunction and loss in AD, with proliferation of vessels around missing vasculature (Meyer et al., 2008). String vessels (black) with no blood cells form as endothelial cells undergo apoptosis. Neutrophils (purple dots) stall a small portion ( $2 \%$ ) of capillaries, reducing blood flow in the network. Penetrating vessels have a tortuous shape, with a tendency to decrease in diameter with aging in AD (Dorr et al., 2012). Capillaries been reported to increase (trending) in diameter in APP/PS1 mice (Lu et al., 2019), experience swelling in APP23 mice (Meyer et al., 2008), decrease in diameter in P301L tau mice (Bennett et al., 2018), and to form "string" vessels with no flow or blood cells in humans (Hunter et al., 2012). Tissue undergoes atrophy, causing vascular shrinkage and functional brain deficits such as memory loss. 
wide distribution of $\mathrm{RBC}$ velocities in capillaries, resulting in reduced oxygen extraction fraction (OEF) from blood vessels by tissues (Kleinfeld et al., 1998; Jespersen and Østergaard, 2012; Østergaard et al., 2015). In contrast, a more homogeneous RBC flux across capillaries and capillary oxygenation yields elevated OEF, which occurs in the case of neuronal stimulation ( $\mathrm{Li} \mathrm{B}$. et al., 2019). Capillary flow patterns are affected by pericytes, dimensions of cells passing through capillaries, glycocalyx, blood composition, and adhesion of cells on vessel walls (Østergaard et al., 2015).

Capillary transit time (the time required for blood to pass through the capillary network) may be observed with 2-photon microscopy by monitoring the passage of a fluorescent dye through the network. A 2-photon study of the TgCRND8 mouse model demonstrated increased transit time dispersion (variability), together with increased transit time, indicative of decreased microvascular network efficiency (Dorr et al., 2012). Transit time dispersion was reduced to non-transgenic levels by treatment with scyllo-inositol, which reduces soluble and insoluble $A \beta$ levels. Since $A \beta$ damages endothelial cells, pericytes, and induces oxidative stress, removal of $A \beta$-induced endothelial dysfunction was interpreted as the reason for return to normal levels. These mice demonstrated an impaired hypercapnic response, which has been observed in both capillaries and arterioles in a transgenic rat model with amyloid and tau pathology (Joo et al., 2017). Impaired homogenization of transit times has been observed in the APP/PS1 mouse model in response to functional activation (Gutiérrez-Jiménez et al., 2018).

2-photon microscopy is not applicable to human studies as it requires invasive surgical procedures such as a craniotomy. Nielsen et al. (2017) performed perfusion MRI to calculate capillary transit time heterogeneity and mean transit time. Elevated mean transit time and capillary transit time heterogeneity in $\mathrm{AD}$ patients correlated with cortical thinning and poor cognitive performance. This study indicated a role for capillary dysfunction in contributing to cognitive decline in humans. Parameters measured in this study included CBF, microvascular cerebral blood volume, and tissue oxygen tension, whose reduction also correlated with poor cognitive performance (Nielsen et al., 2017).

In addition to transit time heterogeneity, MRI techniques (such as dynamic contrast enhanced MRI) may be used to evaluate BBB permeability (Raja et al., 2018).

The vascular changes discussed for the main mice models in this section (Section Vasculature in Alzheimer's Disease) are summarized in a Table $\mathbf{1}$ below.

\section{DISCUSSION AND CONCLUDING THOUGHTS}

Many research issues are unresolved. This includes, for example, the contributions of the various types of $\mathrm{A} \beta$ (monomers, soluble oligomers, and plaques/fibrillar $\mathrm{A} \beta$ ) to $\mathrm{AD}$ (Hillen, 2019), and understanding why amyloid is unsuccessfully cleared and which mechanisms to clear plaques fail in a particular individual.
TABLE 1 | Summary of cerebral vascular changes in the main mouse models highlighted.

\begin{tabular}{|c|c|}
\hline Mouseline & Vascular changes \\
\hline \multirow[t]{3}{*}{ TgCRND8 } & $\begin{array}{l}\text { - Elevated cortical vessel density at P7 and increased } \\
\text { microvascular tortuosity (Durrant et al., 2020) }\end{array}$ \\
\hline & $\begin{array}{l}\text { - Reduced cortical vascular density, increased hippocampal vessel } \\
\text { density at } 6 \text { months (Maliszewska-Cyna et al., 2020). } \\
\text { - Increased hippocampal non-capillary (arterial/venule) tortuosity } \\
\text { (Maliszewska-Cyna et al., 2020). }\end{array}$ \\
\hline & $\begin{array}{l}\text { - Increased cortical penetrating arteriole tortuosity due to amyloid } \\
\text { deposition. Longer transit time (relative to controls) and transit } \\
\text { time variability. Hypercapnia results in transit time increase. No } \\
\text { change in tortuosity of penetrating venules (Dorr et al., 2012; Lai } \\
\text { et al., 2015) }\end{array}$ \\
\hline \multirow[t]{4}{*}{$\operatorname{Tg} 2576$} & - Widespread reductions in CBF at 2-3 months (Niwa et al., 2002) \\
\hline & - BBB disruption at 4 months prior to plaques (Ujiie et al., 2003) \\
\hline & $\begin{array}{l}\text { - Increased cortical capillary density at } 5 \text { months when memory } \\
\text { impaired and plaques not formed; capillary density diminished } \\
\text { by } 27 \text { months (Giuliani et al., 2019) }\end{array}$ \\
\hline & $\begin{array}{l}\text { - Capillary density reduction in white matter at } 10 \text { months (Zhang } \\
\text { et al., 2019) }\end{array}$ \\
\hline \multirow[t]{2}{*}{ APP/PS1 } & $\begin{array}{l}\text { - Cerebral capillaries possess microaneurysms along their lengths, } \\
\text { possible BBB breakdown, at 4-5 months prior to memory } \\
\text { deficits; elevated cortical plaque number at this time point. No } \\
\text { change in capillary diameter or length (Kelly et al., 2017) }\end{array}$ \\
\hline & $\begin{array}{l}\text { - No change in vessel density by } 18 \text { months, but elevated } \\
\text { capillary transit time heterogeneity and reduced capillary blood } \\
\text { flow at rest. Compared to wild types, demonstrate increased } \\
\text { blood flow and capillary flow homogenization in response to } \\
\text { functional activation (Gutiérrez-Jiménez et al., 2018) }\end{array}$ \\
\hline \multirow[t]{2}{*}{ APP23 } & $\begin{array}{l}\text { - At young ages prior to plaques (4-6 months), deposits } \\
\text { containing amyloid attach to capillaries; are associated with } \\
\text { distorted blood vessels. The number and size of holes in the } \\
\text { vascular bed increases. There are indicators of angiogenesis } \\
\text { surrounding the holes (Meyer et al., 2008) }\end{array}$ \\
\hline & $\begin{array}{l}\text { - By } 25-26 \text { months, CAA-associated capillary occlusions in } \\
\text { thalamus cause abnormal blood flow in perforating arteries (Thal } \\
\text { et al., 2009) }\end{array}$ \\
\hline
\end{tabular}

The AH was reviewed, including explanations for failures. Pathological mechanisms beyond amyloid were outlined. Interdisciplinary studies involving microvascular imaging and modeling in mouse models were highlighted, demonstrating microvascular malfunctions that exacerbate AD.

Despite promise in exploring alternative mechanisms, it is premature to abandon the AH. As noted in Walsh and Selkoe (2020), additional analyses of the Phase 3 aducanumab trials indicated that in one trial, there was an " $40 \%$ less decline in activities of daily living than occurred on placebo." With another antibody (BAN2401) demonstrating success in a Phase 2b clinical trial (Walsh and Selkoe, 2020), there are indications that anti-A $\beta$ therapies could reach a breakthrough.

It is important to investigate alternate avenues by which $\mathrm{AD}$ develops beyond $A \beta$. This affects strategies and approaches for designing research activities and development of treatments and drugs. For example, when plaques and tangles are both present, eliminating each simultaneously might be a preferred option rather than amyloid only. If neuroinflammation is widespread, 
clearing amyloid without altering the inflammatory state may not reduce cognitive deficits.

There are numerous $\mathrm{AD}$ hypotheses in addition to $\mathrm{A} \beta$, yet it is difficult to determine the relevancy of each hypothesis, since $\mathrm{AD}$ develops according to genetic, sex, and environmental factors that differ for each subject. $\mathrm{AD}$ could present in a variety of forms, with plaques and tangles in common (Frenkel, 2020). For example, atherosclerosis or cardiac dysfunction may appear in one $\mathrm{AD}$ patient, while be absent in another. This impacts the design of effective treatments since optimal therapies possibly should be "personalized" according to an individual's age, genetics, risk factors, and timing of diagnosis. Frenkel (2020) noted there is the potential of an "arsenal of drugs that can be used to personalize medicine for each patient in the spectrum of diseases associated with AD.” This approach faces challenges, such as determining which "cocktail" of drugs to use and how drugs interact with one another.

Below are two approaches to treat $\mathrm{AD}$ with targeting $\mathrm{A} \beta$ : VEGF therapy and TRPM2 inhibition.

\section{Non-amyloid Treatments \\ VEGF and Growth Factor Therapy}

Due to reduced capillary density with aging, (Ambrose, 2012) proposed VEGF and growth factor administration for restoring capillary density and blood flow. A study in TgCRND8 AD mice overexpressing VEGF found partial recovery of vessel density and restoration of memory impairments, supporting enhancing vascular growth as a method for improving cognition (Religa et al., 2013).

There are factors to consider in applying this therapy to humans. VEGF in high concentrations may induce BBB leakage. Many newly formed vessels during angiogenesis are leaky with abnormal morphology (Vogel et al., 2004). Increasing vessel density alone does not necessarily elevate blood flow (Vogel et al., 2004). In VEGF-overexpressing mice subject to middle cerebral artery occlusion, flow is increased in regions outside the ischemic zone, but reduced within the ischemic/injured tissue core (Wang et al., 2005).

Ambrose (2012) reviews multiple methods for administering growth factors based on animal studies. These include: (1) intravenous delivery via a pump placed under the skin; (2) injection into CSF in ventricles; (3) injection into subarachnoid space above the cerebral hemispheres; (4) magnetic particles loaded with angiogenic factors that are held in the brain via a magnetic skullcap; (5) continuous release of growth factors via direct insertion of a growth factor releasing material into the brain; (6) surgical insertion (i.e., drilling holes in skull) of growth factor-loaded biodegradable material over cortex; (7) injection of growth factors into nasal cavity.

These delivery methods are complicated. For example, a pump placed under the skin would deliver VEGF throughout the body, not only the brain (Ambrose, 2012). Methods involving surgery (injection into CSF, drilling holes in skull) are invasive. A major issue is the growth factors to be delivered. Regrowth of vascular is more than increasing vessel number through administering VEGF. Newly formed vessels adjust their diameters, potentially differentiate into arteries or veins, and recruit support cells such as smooth muscle cells, pericytes, and fibroblasts to produce a functional vessel network (Gale and Yancopoulos, 1999). This network possesses optimal blood flow to satisfy tissue metabolic requirements, and may increase flow through adjusting diameters in response to functional activation of tissue. VEGF stimulates endothelial cell division and migration to form new vessels. Angiopoietin 1 (Ang1) facilitates communication between endothelial and support cells such as smooth muscle cells, stabilizing vessels and acting in conjunction with VEGF to produce a functional network (Gale and Yancopoulos, 1999). Delivery of a single growth factor, such as VEGF, risks producing vessel networks prone to leaks or hemorrhage (Yancopoulos et al., 2000). Expanding growth factor therapy to $\mathrm{AD}$ will require consideration of relative concentrations of naturally occurring growth factors unique to each subject and state of dementia, delivery method, and determining growth factors to administer (i.e., VEGF, Ang1 or 2, FGF, ephrins, etc.), quantity/concentration of growth factors to deliver, and length of time of treatment (i.e., single dose, multiple low-level doses, etc.).

A related therapy to growth factor administration that overcomes some deficiencies is exercise. Exercise increases concentration of a variety of angiogenic molecules such as Ang1 and 2, VEGF, fibroblast growth factor (FGF, upregulates VEGF, and induces vasodilation through nitric oxide), transforming growth factor (TGF, regulates extracellular matrix formation), and platelet derived growth factor (PDGF, mitogen for smooth muscle cells, fibroblasts, and glia cells) (Korivi et al., 2010). Mice provided access to running wheels demonstrated elevated brain microvascular efficiency (Dorr et al., 2017) and increased blood flow in the hippocampus (Cahill et al., 2017). In APP/PS1 mice, exercise restored vessel density and decreased capillary flow heterogeneity in cortex, likely indicating increased oxygen delivery (Lu et al., 2019). Exercise in TgCRND8 mice restored normal capillary density in cortex and hippocampus, and restored hippocampal arterial/venular tortuosity in $\mathrm{AD}$ mice to control levels (Maliszewska-Cyna et al., 2020). Since exercise did not alter parenchymal or vascular amyloid levels, improvements in short-term are possibly attributable to these vascular changes (Maliszewska-Cyna et al., 2020).

\section{Inhibition of Transient Receptor Potential Melastatin 2 (TRPM2)}

TRPM2 is a calcium-permeable ion channel expressed in multiple organs and cell types, including the brain (Turlova et al., 2018). It is activated in response to reactive oxygen species and oxidative stress, permitting calcium to enter the cell and causing neuronal death if the calcium concentration is sufficiently high (Turlova et al., 2018). Our labs demonstrated that eliminating TRPM2 expression or activity in neonatal hypoxic-ischemic injury improves behavioral performance and reduces tissue damage (Huang et al., 2017; Li F. et al., 2019).

Inhibition of TRPM2 activity demonstrates potential in AD. Ostapchenko et al. (2015) demonstrated that APP/PS1 TRPM $2^{-/-}$mice display reduced microglial activation, reversal of memory deficits, and decreased synapse loss. Plaque load or soluble $\mathrm{A} \beta$ peptides were not altered, indicating potential for 
recovery of cognitive function without directly affecting plaque concentration (Ostapchenko et al., 2015).

Activated TRPM2 damages tissue through several mechanisms. It promotes inflammation through cytokine production, and induces BBB dysfunction by allowing calcium into endothelial cells in response to oxidative stress (Belrose and Jackson, 2018). As previously mentioned, $A \beta$ may cause endothelial and vascular dysfunction (such as arterial constriction) by increasing oxidative stress, activating a DNA repair enzyme that opens endothelial TRPM2 channels (Park et al., 2014). Since inhibiting or genetically deleting TRPM2 restores neural activity-induced CBF increases (Park et al., 2014), targeting TRPM2 has potential to restore cerebral vascular function in $\mathrm{AD}$.

Potential mechanisms of TRPM2 action are highlighted in cell culture studies. In human pulmonary artery endothelial cell cultures, inhibition of TRPM2 via small interfering RNA decreased $\mathrm{H}_{2} \mathrm{O}_{2}$-induced intracellular calcium and the consequent increase in endothelial permeability (Hecquet et al., 2008). $\mathrm{Ca}^{2+}$ entry via TRPM 2 may also initiate a process inducing endothelial dysfunction or apoptosis through actions on mitochondria. In cultured pancreatic $\beta$-cells in culture, increase in ROS activates TRPM2, causing $\mathrm{Ca}^{2+}$ cytoplasmic entry and $\mathrm{Zn}^{2+}$ release from lysosomes. $\mathrm{Zn}^{2+}$ binds to mitochondria, inhibiting the electron transport chain and leading to membrane potential loss that recruits dynamin-related protein1 (Drp1). Drp1 "slices" the mitochondria, causing mitochondrial fission and apoptosis (Li et al., 2017a,b). A similar process occurs in cultures of endothelial cells in response to increased ROS (Abuarab et al., 2017), with hippocampal neurons exposed to $A \beta$ also demonstrating zinc accumulation in mitochondria and mitochondrial dysfunction (Li and Jiang, 2018).

Scalaradial, a marine extract, is a potent TRPM2 inhibitor, although it partially inhibits TRPM7 as well (Starkus et al., 2017). Its mechanism is unknown. Generally, while TRPM2 inhibitors exist, they lack potency or are non-specific (Starkus et al., 2017).

\section{Looking Ahead and Thoughts}

Restoring blood flow in early stages of $\mathrm{AD}$ progression could limit dementia progression. Korte et al. (2020) outline additional therapeutic approaches targeting blood flow. Capillary constriction via pericytes occurs via $A \beta$-oligomer production of ROS from pericytes and microglia and activation of endothelin A receptors that bind endothelin (a vasoconstrictor). Relaxing pericytes via voltage-gated calcium channel (VGCC) inhibition is a therapeutic target, with a VGCC-inhibitor (nilvadipine, normally used for hypertension) restoring cortical CBF in 13month old Tg2576 mice, and hippocampal CBF in humans with mild-moderate AD (Paris et al., 2004b; de Jong et al., 2019; Korte et al., 2020). Additional therapies suggested by Korte et al. (2020) include preventing occluded capillaries through neutrophil targeting and anticoagulants to enhance blood flow. However, depletion of neutrophils may lead to infection, while anticlotting agents could induce hemorrhage (Korte et al., 2020).

A limitation in developing vascular-based drugs is animal models. A 3D microscopy analysis revealed amyloid plaques in human tissue were larger and more complex than those in mice, displaying a wider variety of sizes and shapes compared to those in mice (Liebmann et al., 2016). Consequently, successful removal of plaques from mice does not necessarily correspond to an identical situation in humans. Other limitations of transgenic rodent models are detailed in Braidy et al. (2012) such as difficulties in modeling tau pathology and lack of neurodegeneration. In vitro models, while valuable for investigating molecular mechanisms, face limits in translation to humans due to inability to account for multiple cellular interactions that affect endothelial cells. Progress has been made on this front through development of a 3D in vitro microfluidic culture model containing neurons (developed from progenitor cells) with mutations in APP and APP/PS1 genes, aggregation of extracellular $\mathrm{A} \beta$, hyperphosphorylated tau, and mimicking $\mathrm{BBB}$ disruption with aggregation of $A \beta$ on vascular wall (Choi et al., 2014; Kim et al., 2015; Shin et al., 2019). This culture model could be used to screen whether drugs cross the BBB and their effect on different cell types (Shin et al., 2019).

Despite our vascular focus, AD pathology may be improved through treatments that induce negative vascular effects. For example, nilotinib, a tyrosine kinase inhibitor normally used to treat leukemia, was administered to individuals with $\mathrm{AD}$ mild to moderate dementia in a phase 2 clinical trial (Turner et al., 2020). Nilotinib reduced CSF A $\beta$ (40 and 42 ), minimized hippocampal volume loss, and reduced frontal lobe amyloid (Turner et al., 2020). However, nilotinib inhibits endothelial cell proliferation in culture, while inhibiting angiogenesis and blood flow following hind-limb ischemia in mice (Hadzijusufovic et al., 2017). Arterial occlusive disease developed in nilotinib-treated patients, while atherosclerosis and a pro-atherogenic phenotype was promoted in mice models and endothelial cultures respectively (Hadzijusufovic et al., 2017).

Early AD detection is necessary to deliver treatment prior to permanent tissue damage. Kosik (2013) proposed observing activity of collections of neurons, which may show subtle alterations not detectable with standard neuropsychological testing. Such changes could be detectable with resting state functional MRI to monitor connectivity between brain regions (Brier et al., 2014). This is supported by findings in mice, where regional neuronal activity determines location of $A \beta$ deposition (Bero et al., 2011). Some studies note that in humans reduced blood flow precedes cognitive decline (Iturria-Medina et al., 2016), with impaired reactivity to hypercapnia a biomarker of disease (Glodzik et al., 2013).

It is necessary to consider multiple avenues by which $\mathrm{AD}$ develops beyond strictly $A \beta$ in developing pharmacological approaches. The $\mathrm{AH}$ remains prominent, although reservations have been raised as to its underlying assumption of amyloid as the central feature of $\mathrm{AD}$ pathology. As research continues testing more hypotheses, a continued flexibility in approach is required beyond the belief that eliminating plaques $/ \mathrm{A} \beta$ alone will lead to a cure.

A single treatment approach could be considered for early onset $\mathrm{AD}$ since this form of the disease is often dependent on APP-related genetics. Most cases, however, are late-onset 
and depend on genetic elements beyond $\mathrm{A} \beta$. Consideration should be given to treating multiple mechanisms simultaneously, such as removing plaques through antibodies and reducing inflammation through non-steroidal anti-inflammatories. This approach does not entail abandoning $A \beta$, but viewing it as an important element of $\mathrm{AD}$ pathology that acts in combination with other mechanisms.

To target multiple sites, there are issues to be addressed. For example, is amyloid build-up due to decreased LRP1 expression at the blood brain barrier, reduced neprilysin production, or the glymphatic system and arterial stiffening? And how can these be detected through imaging or biomarkers? To address these issues, the investigator requires understanding the biological mechanisms involved in disease progression, and consequences of therapeutic targeting of these mechanisms while omitting others.

\section{REFERENCES}

Abrahamson, E. E., and Ikonomovic, M. D. (2020). Brain injury-induced dysfunction of the blood brain barrier as a risk for dementia. Exp. Neurol. 328:113257. doi: 10.1016/j.expneurol.2020.113257

Abuarab, N., Munsey, T. S., Jiang, L. H., Li, J., and Sivaprasadarao, A. (2017). High glucose-induced ROS activates TRPM2 to trigger lysosomal membrane permeabilization and $\mathrm{Zn} 2+$-mediated mitochonfrial fission. Sci. Signal. 10:eaa14161. doi: 10.1126/scisignal.aal4161

Ahluwalia, A., Jones, M. K., Deng, X., Sandor, Z., Szabo, S., and Tarnawski, A. S. (2013). An imbalance between VEGF and endostatin underlies impaired angiogenesis in gastric mucosa of aging rats. Am. J. Physiol. Gastrointest. Liver Physiol. 305, G325-G332. doi: 10.1152/ajpgi.00127.2013

Ambrose, C. T. (2012). Neuroangiogenesis: a vascular basis for Alzheimer's disease and cognitive decline during aging. J. Alzheimers Dis. 32, 773-788. doi: 10.3233/JAD-2012-120067

Ambrose, C. T. (2017). Pro-angiogenesis therapy and aging: a mini-review. Gerontology 63, 393-400. doi: 10.1159/000477402

Andersen, K., Launer, L. J., Ott, A., Hoes, A. W., Breteler, M. M., and Hofman, A. (1995). Do nonsteroidal anti-inflammatory drugs decrease the risk for Alzheimer's disease? The Rotterdam Study. Neurology 45, 1441-1445. doi: 10.1212/WNL.45.8.1441

Bangen, K. J., Restom, K., Liu, T. T., Wierenga, C. E., Jak, A. J., Salmon, D. P., et al. (2012). Assessment of Alzheimer's disease risk with functional magnetic resonance imaging: an arterial spin labeling study. J. Alzheimers Dis. 31(Suppl 3), S59-S74. doi: 10.3233/JAD-2012-120292

Bejanin, A., Schonhaut, D. R., La Joie, R., Kramer, J. H., Baker, S. L., Sosa, N., et al. (2017). Tau pathology and neurodegeneration contribute to cognitive impairment in Alzheimer's disease. Brain 140, 3286-3300. doi: 10.1093/brain/awx243

Belrose, J. C., and Jackson, M. F. (2018). TRPM2: a candidate therapeutic target for treating neurological diseases. Acta Pharmacol. Sin 39, 722-732. doi: 10.1038/aps.2018.31

Benderro, G. F., and Lamanna, J. C. (2011). Hypoxia-induced angiogenesis is delayed in aging mouse brain. Brain Res. 1389, 50-60. doi: 10.1016/j.brainres.2011.03.016

Bennett, R. E., Robbins, A. B., Hu, M., Cao, X., Betensky, R. A., Clark, T., et al. (2018). Tau induces blood vessel abnormalities and angiogenesis-related gene expression in P301L transgenic mice and human Alzheimer's disease. Proc. Natl. Acad. Sci. U. S. A. 115, E1289-E1298. doi: 10.1073/pnas.17103 29115

Bero, A. W., Yan, P., Roh, J. H., Cirrito, J. R., Stewart, F. R., Raichle, M. E., et al. (2011). Neuronal activity regulates the regional vulnerability to amyloid- $\beta$ deposition. Nat. Neurosci. 14, 750-756. doi: 10.1038/nn.2801

Berthiaume, A. A., Grant, R. I., McDowell, K. P., Underly, R. G., Hartmann, D. A., Levy, M., et al. (2018). Dynamic remodeling of pericytes in vivo
Future research will continue to focus on the many issues covered in this review. Hopefully, this will lead to new research directions and treatments, and improve or prevent cognitive decline in patients.

\section{AUTHOR CONTRIBUTIONS}

All authors listed have made a substantial, direct and intellectual contribution to the work, and approved it for publication.

\section{ACKNOWLEDGMENTS}

This work was supported by grants from Canadian Institutes of Health Research to ZPF (PJT-153155) and the Natural Sciences and Engineering Research Council of Canada to HSS (RGPIN2016-04574).

maintains capillary coverage in the adult mouse brain. Cell Rep. 22, 8-16. doi: 10.1016/j.celrep.2017.12.016

Bertram, L., and Tanzi, R. E. (2019). Alzheimer disease risk genes: 29 and counting. Nat. Rev. Neurol. 15, 191-192. doi: 10.1038/s41582-019-0158-4

Biber, K., Bhattacharya, A., Campbell, B. M., Piro, J. R., Rohe, M., Staal, R. G. W., et al. (2019). Microglial drug targets in AD: opportunities and challenges in drug discovery and development. Front. Pharmacol. 10:840. doi: 10.3389/fphar.2019.00840

Biron, K. E., Dickstein, D. L., Gopaul, R., Fenninger, F., and Jefferies, W. A. (2013). Cessation of neoangiogenesis in Alzheimer's disease follows amyloidbeta immunization. Sci. Rep 3:1354. doi: 10.1038/srep01354

Biron, K. E., Dickstein, D. L., Gopaul, R., and Jefferies, W. A. (2011). Amyloid triggers extensive cerebral angiogenesis causing blood brain barrier permeability and hypervascularity in Alzheimer's disease. PLoS One 6:e23789. doi: 10.1371/journal.pone.0023789

Blurton-Jones, M., and Laferla, F. M. (2006). Pathways by which Abeta facilitates tau pathology. Curr. Alzheimer Res. 3, 437-448. doi: 10.2174/156720506779025242

Boche, D., Zotova, E., Weller, R. O., Love, S., Neal, J. W., Pickering, R. M., et al. (2008). Consequence of Abeta immunization on the vasculature of human Alzheimer's disease brain. Brain 131(Pt 12), 3299-3310. doi: 10.1093/brain/awn261

Boudier, H. A. (1999). Arteriolar and capillary remodelling in hypertension. Drugs 58, 37-40.

Braak, H., and Del Tredici, K. (2011). The pathological process underlying Alzheimer's disease in individuals under thirty. Acta Neuropathol. 121, 171-181. doi: 10.1007/s00401-010-0789-4

Bracko, O., Njiru, B. N., Swallow, M., Ali, M., Haft-Javaherian, M., and Schaffer, C. B. (2020). Increasing cerebral blood flow improves cognition into late stages in Alzheimer's disease mice. J. Cereb. Blood Flow Metab. 40, 1441-1452. doi: 10.1177/0271678X19873658

Braidy, N., Muñoz, P., Palacios, A. G., Castellano-Gonzalez, G., Inestrosa, N. C., Chung, R. S., et al. (2012). Recent rodent models for Alzheimer's disease: clinical implications and basic research. J Neural Transm. 119, 173-195. doi: 10.1007/s00702-011-0731-5

Brier, M. R., Thomas, J. B., and Ances, B. M. (2014). Network dysfunction in Alzheimer's disease: refining the disconnection hypothesis. Brain Connect. 4, 299-311. doi: 10.1089/brain.2014.0236

Brinton, R. D. (2008). The healthy cell bias of estrogen action: mitochondrial bioenergetics and neurological implications. Trends Neurosci. 31, 529-537. doi: 10.1016/j.tins.2008.07.003

Brown, W. R., and Thore, C. R. (2011). Review: cerebral microvascular pathology in ageing and neurodegeneration. Neuropathol. Appl. Neurobiol. 37, 56-74. doi: 10.1111/j.1365-2990.2010.01139.x

Cahill, L. S., Bishop, J., Gazdzinski, L. M., Dorr, A., Stefanovic, B., and Sled, J. G. (2017). Altered cerebral blood flow and cerebrovascular function 
after voluntary exercise in adult mice. Brain Struct. Funct. 222, 3395-3405. doi: 10.1007/s00429-017-1409-Z

Cai, Z., Liu, Z., Xiao, M., Wang, C., and Tian, F. (2017). Chronic cerebral hypoperfusion promotes amyloid-beta pathogenesis via activating $\beta / \gamma$ secretases. Neurochem. Res. 42, 3446-3455. doi: 10.1007/s11064-017-2391-9

Calderón-Garcidueñas, L., Franco-Lira, M., Henríquez-Roldán, C., Osnaya, N., González-Maciel, A., Reynoso-Robles, R., et al. (2010). Urban air pollution: influences on olfactory function and pathology in exposed children and young adults. Exp. Toxicol. Pathol. 62, 91-102. doi: 10.1016/j.etp.2009.02.117

Carmona, S., Zahs, K., Wu, E., Dakin, K., Bras, J., and Guerreiro, R. (2018). The role of TREM2 in Alzheimer's disease and other neurodegenerative disorders. Lancet Neurol. 17, 721-730. doi: 10.1016/S1474-4422(18)30232-1

Carroll, J. C., Rosario, E. R., Chang, L., Stanczyk, F. Z., Oddo, S., LaFerla, F. M., et al. (2007). Progesterone and estrogen regulate Alzheimer-like neuropathology in female 3xTg-AD mice. J. Neurosci. 27, 13357-13365. doi: 10.1523/JNEUROSCI.2718-07.2007

Choi, S. H., Kim, Y. H., Hebisch, M., Sliwinski, C., Lee, S., D’Avanzo, C., et al. (2014). A three-dimensional human neural cell culture model of Alzheimer's disease. Nature 515, 274-278. doi: 10.1038/nature13800

Cramer, P. E., Cirrito, J. R., Wesson, D. W., Lee, C. Y., Karlo, J. C., Zinn, A. E., et al. (2012). ApoE-directed therapeutics rapidly clear $\beta$-amyloid and reverse deficits in AD mouse models. Science 335, 1503-1506. doi: 10.1126/science.1217697

Cruz Hernández, J. C., Bracko, O., Kersbergen, C. J., Muse, V., Haft-Javaherian, M., Berg, M., et al. (2019). Neutrophil adhesion in brain capillaries reduces cortical blood flow and impairs memory function in Alzheimer's disease mouse models. Nat. Neurosci. 22, 413-420. doi: 10.1038/s41593-018-0329-4

Das, P., Murphy, M. P., Younkin, L. H., Younkin, S. G., and Golde, T. E. (2001). Reduced effectiveness of A $31-42$ immunization in APP transgenic mice with significant amyloid deposition. Neurobiol. Aging 22, 721-727. doi: 10.1016/S0197-4580(01)00245-7

de Jong, D. L. K., de Heus, R. A. A., Rijpma, A., Donders, R., Olde Rikkert, M. G. M., Günther, M., et al. (2019). Effects of nilvadipine on cerebral blood flow in patients with Alzheimer disease. Hypertension 74, 413-420. doi: 10.1161/HYPERTENSIONAHA.119.12892

de la Torre, J. C. (1994). Impaired brain microcirculation may trigger Alzheimer's disease. Neurosci. Biobehav. Rev. 18, 397-401. doi: 10.1016/0149-7634(94)90052-3

de la Torre, J. C., and Mussivand, T. (1993). Can disturbed brain microcirculation cause Alzheimer's disease? Neurol. Res. 15, 146-153. doi: 10.1080/01616412.1993.11740127

de Paula, V. J. R., Guimarães, F. M., Diniz, B. S., and Forlenza, O. V. (2009). Neurobiological pathways to Alzheimer's disease: amyloid- $\beta$, TAU protein or both? Dement. Neuropsychol. 3, 188-194. doi: 10.1590/S1980-57642009DN30300003

De Servi, B., La Porta, C. A., Bontempelli, M., and Comolli, R. (2002). Decrease of TGF- $\beta 1$ plasma levels and increase of nitric oxide synthase activity in leukocytes as potential biomarkers of Alzheimer's disease. Exp. Gerontol. 37, 813-821. doi: 10.1016/S0531-5565(02)00018-9

Deane, R., Bell, R. D., Sagare, A., and Zlokovic, B. V. (2009). Clearance of amyloid-beta peptide across the blood-brain barrier: implication for therapies in Alzheimer's disease. CNS Neurol. Disord. Drug Targets 8, 16-30. doi: $10.2174 / 187152709787601867$

Deane, R. J. (2012). Is RAGE still a therapeutic target for Alzheimer's disease? Future Med. Chem. 4, 915-925. doi: 10.4155/ fmc. 12.51

Demattos, R. B., Lu, J., Tang, Y., Racke, M. M., Delong, C. A., Tzaferis, J. A., et al. (2012). A plaque-specific antibody clears existing $\beta$ amyloid plaques in Alzheimer's disease mice. Neuron 76, 908-920. doi: 10.1016/j.neuron.2012.10.029

Desai, B. S., Schneider, J. A., Li, J. L., Carvey, P. M., and Hendey, B. (2009). Evidence of angiogenic vessels in Alzheimer's disease. J. Neural Transm. 116, 587-597. doi: 10.1007/s00702-009-0226-9

Di, J., Cohen, L. S., Corbo, C. P., Phillips, G. R., El Idrissi, A., and Alonso, A. D. (2016). Abnormal tau induces cognitive impairment through two different mechanisms: synaptic dysfunction and neuronal loss. Sci. Rep. 6:20833. doi: 10.1038/srep20833

Ding, Q., Dimayuga, E., Martin, S., Bruce-Keller, A. J., Nukala, V., Cuervo, A. M., et al. (2003). Characterization of chronic low-level proteasome inhibition on neural homeostasis. J. Neurochem. 86, 489-497. doi: 10.1046/j.1471-4159.2003.01885.x

Doens, D., and Fernández, P. L. (2014). Microglia receptors and their implications in the response to amyloid $\beta$ for Alzheimer's disease pathogenesis. J. Neuroinflammation 11:48. doi: 10.1186/1742-2094-11-48

Dorr, A., Sahota, B., Chinta, L. V., Brown, M. E., Lai, A. Y., Ma, K., et al. (2012). Amyloid- $\beta$-dependent compromise of microvascular structure and function in a model of Alzheimer's disease. Brain 135(Pt 10), 3039-3050. doi: 10.1093/brain/aws243

Dorr, A., Thomason, L. A., Koletar, M. M., Joo, I. L., Steinman, J., Cahill, L. S., et al. (2017). Effects of voluntary exercise on structure and function of cortical microvasculature. J. Cereb. Blood Flow Metab. 37, 1046-1059. doi: 10.1177/0271678X16669514

DuBoff, B., Götz, J., and Feany, M. B. (2012). Tau promotes neurodegeneration via DRP1 mislocalization in vivo. Neuron 75, 618-632. doi: 10.1016/j.neuron.2012.06.026

Durrant, C. S., Ruscher, K., Sheppard, O., Coleman, M. P., and Özen, I. (2020). Beta secretase 1-dependent amyloid precursor protein processing promotes excessive vascular sprouting through NOTCH3 signalling. Cell Death Dis. 11, 98. doi: 10.1038/s41419-020-2288-4

Evin, G., Sernee, M. F., and Masters, C. L. (2006). Inhibition of gamma-secretase as a therapeutic intervention for Alzheimer's disease: prospects, limitations and strategies. CNS Drugs 20, 351-372. doi: 10.2165/00023210-200620050-00002

Extance, A. (2010). Alzheimer's failure raises questions about disease-modifying strategies. Nat. Rev. Drug Discov. 9, 749-751. doi: 10.1038/nrd3288

Farkas, E., and Luiten, P. G. (2001). Cerebral microvascular pathology in aging and Alzheimer's disease. Prog. Neurobiol. 64, 575-611. doi: 10.1016/S0301-0082(00)00068-X

Ferretti, M. T., Iulita, M. F., Cavedo, E., Chiesa, P. A., Schumacher Dimech, A., Santuccione Chadha, A., et al. (2018). Sex differences in Alzheimer disease - the gateway to precision medicine. Nat. Rev. Neurol. 14, 457-469. doi: 10.1038/s41582-018-0032-9

Ferris, S. H., and Farlow, M. (2013). Language impairment in Alzheimer's disease and benefits of acetylcholinesterase inhibitors. Clin. Interv. Aging 8, 1007-1014. doi: 10.2147/CIA.S39959

Fleisher, A. S., Podraza, K. M., Bangen, K. J., Taylor, C., Sherzai, A., Sidhar, K., et al. (2009). Cerebral perfusion and oxygenation differences in Alzheimer's disease risk. Neurobiol. Aging 30, 1737-1748. doi: 10.1016/j.neurobiolaging.2008.01.012

Floden, A. M., Li, S., and Combs, C. K. (2005). Beta-amyloid-stimulated microglia induce neuron death via synergistic stimulation of tumor necrosis factor alpha and NMDA receptors. J. Neurosci. 25, 2566-2575. doi: 10.1523/JNEUROSCI.4998-04.2005

Fonck, E., Feigl, G. G., Fasel, J., Sage, D., Unser, M., Rüfenacht, D. A., et al. (2009). Effect of aging on elastin functionality in human cerebral arteries. Stroke 40, 2552-2556. doi: 10.1161/STROKEAHA.108.528091

Frenkel, D. (2020). Alzheimer's disease: a need for personalized therapeutic approaches. Drug Dev. Res. 81, 141-143. doi: 10.1002/ddr.21652

Frisoni, G. B., and Blennow, K. (2013). Biomarkers for Alzheimer's: the sequel of an original model. Lancet Neurol. 12, 126-128. doi: 10.1016/S1474-4422(12)70305-8

Gale, N. W., and Yancopoulos, G. D. (1999). Growth factors acting via endothelial cell-specific receptor tyrosine kinases: VEGFs, angiopoietins, and ephrins in vascular development. Genes Dev. 13, 1055-1066. doi: 10.1101/gad.13.9.1055

Gallardo, G., and Holtzman, D. M. (2017). Antibody therapeutics targeting $\mathrm{A} \beta$ and tau. Cold Spring Harb. Perspect. Med. 7:a024331. doi: 10.1101/cshperspect.a024331

Gilman, S., Koller, M., Black, R. S., Jenkins, L., Griffith, S. G., Fox, N. C., et al. (2005). Clinical effects of A $\beta$ immunization (AN1792) in patients with AD in an interrupted trial. Neurology 64, 1553-1562. doi: 10.1212/01.WNL.0000159740.16984.3C

Giuliani, A., Sivilia, S., Baldassarro, V. A., Gusciglio, M., Lorenzini, L., Sannia, M., et al. (2019). Age-related changes of the neurovascular unit in the cerebral cortex of Alzheimer disease mouse models: a neuroanatomical and molecular study. J. Neuropathol. Exp. Neurol. 78, 101-112. doi: 10.1093/jnen/nly125

Glodzik, L., Randall, C., Rusinek, H., and de Leon, M. J. (2013). Cerebrovascular reactivity to carbon dioxide in Alzheimer's disease. J. Alzheimers Dis. 35, 427-440. doi: 10.3233/JAD-122011 
Govindpani, K., McNamara, L. G., Smith, N. R., Vinnakota, C., Waldvogel, H. J., Faull, R. L., et al. (2019). Vascular dysfunction in Alzheimer's disease: a prelude to the pathological process or a consequence of it? J. Clin. Med. 8:651. doi: $10.3390 / \mathrm{jcm} 8050651$

Greenberg, S. M., Bacskai, B. J., Hernandez-Guillamon, M., Pruzin, J., Sperling, R., and van Veluw, S. J. (2020). Cerebral amyloid angiopathy and Alzheimer disease - one peptide, two pathways. Nat. Rev. Neurol. 16, 30-42. doi: 10.1038/s41582-019-0281-2

Griciuc, A., Serrano-Pozo, A., Parrado, A. R., Lesinski, A. N., Asselin, C. N., Mullin, K., et al. (2013). Alzheimer's disease risk gene CD33 inhibits microglial uptake of amyloid beta. Neuron 78, 631-643. doi: 10.1016/j.neuron.201 3.04.014

Gupta, A., and Iadecola, C. (2015). Impaired A $\beta$ clearance: a potential link between atherosclerosis and Alzheimer's disease. Front. Aging Neurosci. 7:115. doi: 10.3389/fnagi.2015.00115

Gutiérrez-Jiménez, E., Angleys, H., Rasmussen, P. M., West, M. J., Catalini, L., Iversen, N. K., et al. (2018). Disturbances in the control of capillary flow in an aged APP. Neurobiol. Aging 62, 82-94. doi: 10.1016/j.neurobiolaging.2017.10.006

Hadzijusufovic, E., Albrecht-Schgoer, K., Huber, K., Hoermann, G., Grebien, F., Eisenwort, G., et al. (2017). Nilotinib-induced vasculopathy: identification of vascular endothelial cells as a primary target site. Leukemia 31, 2388-2397. doi: 10.1038/leu.2017.245

Hall, C. N., Reynell, C., Gesslein, B., Hamilton, N. B., Mishra, A., Sutherland, B. A., et al. (2014). Capillary pericytes regulate cerebral blood flow in health and disease. Nature 508, 55-60. doi: 10.1038/nature13165

Hansen, D. V., Hanson, J. E., and Sheng, M. (2018). Microglia in Alzheimer's disease. J. Cell Biol. 217, 459-472. doi: 10.1083/jcb.201709069

Hardy, J. A., and Higgins, G. A. (1992). Alzheimer's disease: the amyloid cascade hypothesis. Science 256, 184-185. doi: 10.1126/science.1566067

Harrison, T. M., La Joie, R., Maass, A., Baker, S. L., Swinnerton, K., Fenton, L., et al. (2019). Longitudinal tau accumulation and atrophy in aging and alzheimer disease. Ann. Neurol. 85, 229-240. doi: 10.1002/ana.25406

Hawkes, C. A., and McLaurin, J. (2009). Selective targeting of perivascular macrophages for clearance of beta-amyloid in cerebral amyloid angiopathy. Proc. Natl. Acad. Sci. U. S. A. 106, 1261-1266. doi: 10.1073/pnas.0805453106

Hecht, M., Krämer, L. M., von Arnim, C. A. F., Otto, M., and Thal, D. R. (2018). Capillary cerebral amyloid angiopathy in Alzheimer's disease: association with allocortical/hippocampal microinfarcts and cognitive decline. Acta Neuropathol. 135, 681-694. doi: 10.1007/s00401-018-1834-y

Hecquet, C. M., Ahmmed, G. U., Vogel, S. M., and Malik, A. B. (2008). Role of TRPM2 channel in mediating $\mathrm{H}_{2} \mathrm{O}_{2}$-induced $\mathrm{Ca}^{2+}$ entry and endothelial hyperpermeability. Circ. Res. 102, 347-355. doi: 10.1161/CIRCRESAHA.107.160176

Hemonnot, A. L., Hua, J., Ulmann, L., and Hirbec, H. (2019). Microglia in Alzheimer disease: well-known targets and new opportunities. Front. Aging Neurosci. 11:233. doi: 10.3389/fnagi.2019.00233

Henderson, V. W., and Brinton, R. D. (2010). Menopause and mitochondria: windows into estrogen effects on Alzheimer's disease risk and therapy. Prog. Brain Res. 182, 77-96. doi: 10.1016/S0079-6123(10)82003-5

Heneka, M. T., Sastre, M., Dumitrescu-Ozimek, L., Hanke, A., Dewachter, I., Kuiperi, C., et al. (2005). Acute treatment with the PPARgamma agonist pioglitazone and ibuprofen reduces glial inflammation and $A \beta 1$ 42 levels in APPV717I transgenic mice. Brain 128(Pt 6), 1442-1453. doi: 10.1093/brain/awh452

Hernandez, F., Lucas, J. J., and Avila, J. (2013). GSK3 and tau: two convergence points in Alzheimer's disease. J. Alzheimers Dis. 33(Suppl 1), S141-S144. doi: 10.3233/JAD-2012-129025

Herrup, K. (2010). Reimagining Alzheimer's disease-an age-based hypothesis. J. Neurosci. 30, 16755-16762. doi: 10.1523/JNEUROSCI.452110.2010

Hillen, H. (2019). The beta amyloid dysfunction (BAD) hypothesis for Alzheimer's disease. Front. Neurosci. 13:1154. doi: 10.3389/fnins.2019.01154

Hollingworth, P., Harold, D., Sims, R., Gerrish, A., Lambert, J. C., Carrasquillo, M. M., et al. (2011). Common variants at ABCA7, MS4A6A/MS4A4E, EPHA1, CD33 and CD2AP are associated with Alzheimer's disease. Nat. Genet. 43, 429-435. doi: 10.1038/ng.803
Holmes, C., Boche, D., Wilkinson, D., Yadegarfar, G., Hopkins, V., Bayer, A., et al. (2008). Long-term effects of A $\beta 42$ immunisation in Alzheimer's disease: followup of a randomised, placebo-controlled phase I trial. Lancet 372, 216-223. doi: 10.1016/S0140-6736(08)61075-2

Hooijmans, C. R., Graven, C., Dederen, P. J., Tanila, H., van Groen, T., and Kiliaan, A. J. (2007). Amyloid beta deposition is related to decreased glucose transporter-1 levels and hippocampal atrophy in brains of aged APP/PS1 mice. Brain Res. 1181, 93-103. doi: 10.1016/j.brainres.2007.08.063

Huang, L., Jia, J., and Liu, R. (2013). Decreased serum levels of the angiogenic factors VEGF and TGF- $\beta 1$ in Alzheimer's disease and amnestic mild cognitive impairment. Neurosci. Lett. 550, 60-63. doi: 10.1016/j.neulet.2013.06.031

Huang, S., Turlova, E., Li, F., Bao, M. H., Szeto, V., Wong, R., et al. (2017). Transient receptor potential melastatin 2 channels (TRPM2) mediate neonatal hypoxic-ischemic brain injury in mice. Exp. Neurol. 296, 32-40. doi: 10.1016/j.expneurol.2017.06.023

Hunter, J. M., Kwan, J., Malek-Ahmadi, M., Maarouf, C. L., Kokjohn, T. A., Belden, C., et al. (2012). Morphological and pathological evolution of the brain microcirculation in aging and Alzheimer's disease. PLoS One 7:e36893. doi: 10.1371/journal.pone.0036893

Iadecola, C., Zhang, F., Niwa, K., Eckman, C., Turner, S. K., Fischer, E., et al. (1999). SOD1 rescues cerebral endothelial dysfunction in mice overexpressing amyloid precursor protein. Nat. Neurosci. 2, 157-161. doi: 10.1038/5715

Iliff, J. J., Wang, M., Liao, Y., Plogg, B. A., Peng, W., Gundersen, G. A., et al. (2012). A paravascular pathway facilitates CSF flow through the brain parenchyma and the clearance of interstitial solutes, including amyloid $\beta$. Sci. Transl. Med. 4:147ra111. doi: 10.1126/scitranslmed.3003748

Iliff, J. J., Wang, M., Zeppenfeld, D. M., Venkataraman, A., Plog, B. A., Liao, Y., et al. (2013). Cerebral arterial pulsation drives paravascular CSFinterstitial fluid exchange in the murine brain. J. Neurosci. 33, 18190-18199. doi: 10.1523/JNEUROSCI.1592-13.2013

Iturria-Medina, Y., Sotero, R. C., Toussaint, P. J., Mateos-Pérez, J. M., Evans, A. C., Initiative, A., et al. (2016). Early role of vascular dysregulation on late-onset Alzheimer's disease based on multifactorial data-driven analysis. Nat. Commun. 7:11934. doi: 10.1038/ncomms11934

Jack, C. R., Knopman, D. S., Jagust, W. J., Petersen, R. C., Weiner, M. W., Aisen, P. S., et al. (2013). Tracking pathophysiological processes in Alzheimer's disease: an updated hypothetical model of dynamic biomarkers. Lancet Neurol. 12, 207-216. doi: 10.1016/S1474-4422(12)70291-0

Jefferies, W. A., Price, K. A., Biron, K. E., Fenninger, F., Pfeifer, C. G., and Dickstein, D. L. (2013). Adjusting the compass: new insights into the role of angiogenesis in Alzheimer's disease. Alzheimers. Res. Ther. 5, 64. doi: 10.1186/alzrt230

Jespersen, S. N., and Østergaard, L. (2012). The roles of cerebral blood flow, capillary transit time heterogeneity, and oxygen tension in brain oxygenation and metabolism. J. Cereb. Blood Flow Metab. 32, 264-277. doi: $10.1038 /$ jcbfm. 2011.153

Joo, I. L., Lai, A. Y., Bazzigaluppi, P., Koletar, M. M., Dorr, A., Brown, M. E., et al. (2017). Early neurovascular dysfunction in a transgenic rat model of Alzheimer's disease. Sci. Rep. 7:46427. doi: 10.1038/srep46427

Kametani, F., and Hasegawa, M. (2018). Reconsideration of amyloid hypothesis and tau hypothesis in Alzheimer's disease. Front. Neurosci. 12:25. doi: 10.3389/fnins.2018.00025

Kelly, P., Denver, P., Satchell, S. C., Ackermann, M., Konerding, M. A., and Mitchell, C. A. (2017). Microvascular ultrastructural changes precede cognitive impairment in the murine APPswe/PS1dE9 model of Alzheimer's disease. Angiogenesis 20, 567-580. doi: 10.1007/s10456-017-9568-3

Killin, L. O., Starr, J. M., Shiue, I. J., and Russ, T. C. (2016). Environmental risk factors for dementia: a systematic review. BMC Geriatr. 16:175. doi: 10.1186/s12877-016-0342-y

Kim, Y. H., Choi, S. H., D’Avanzo, C., Hebisch, M., Sliwinski, C., Bylykbashi, E., et al. (2015). A 3D human neural cell culture system for modeling Alzheimer's disease. Nat. Protoc. 10, 985-1006. doi: 10.1038/nprot.2015.065

Kim, Y. N., and Kim, D. H. (2012). Decreased serum angiogenin level in Alzheimer's disease. Prog. Neuropsychopharmacol. Biol. Psychiatry 38, 116-120. doi: 10.1016/j.pnpbp.2012.02.010

Kisler, K., Nelson, A. R., Rege, S. V., Ramanathan, A., Wang, Y., Ahuja, A., et al. (2017). Pericyte degeneration leads to neurovascular uncoupling and limits oxygen supply to brain. Nat. Neurosci. 20, 406-416. doi: 10.1038/nn.4489 
Kleinfeld, D., Mitra, P. P., Helmchen, F., and Denk, W. (1998). Fluctuations and stimulus-induced changes in blood flow observed in individual capillaries in layers 2 through 4 of rat neocortex. Proc. Natl. Acad. Sci. USA, 95: 15741-15746. doi: $10.1073 /$ pnas.95.26.15741

Klohs, J. (2019). An integrated view on vascular dysfunction in Alzheimer's disease. Neurodegener. Dis. 19, 109-127. doi: 10.1159/000505625

Klohs, J., Rudin, M., Shimshek, D. R., and Beckmann, N. (2014). Imaging of cerebrovascular pathology in animal models of Alzheimer's disease. Front. Aging Neurosci. 6:32. doi: 10.3389/fnagi.2014.00032

Knowles, R. B., Wyart, C., Buldyrev, S. V., Cruz, L., Urbanc, B., Hasselmo, M. E., et al. (1999). Plaque-induced neurite abnormalities: implications for disruption of neural networks in Alzheimer's disease. Proc. Natl. Acad. Sci. U. S. A. 96, 5274-5279. doi: 10.1073/pnas.96.9.5274

Koffie, R. M., Meyer-Luehmann, M., Hashimoto, T., Adams, K. W., Mielke, M. L., Garcia-Alloza, M., et al. (2009). Oligomeric amyloid beta associates with postsynaptic densities and correlates with excitatory synapse loss near senile plaques. Proc. Natl. Acad. Sci. U. S. A. 106, 4012-4017. doi: 10.1073/pnas.0811698106

Koike, M. A., Green, K. N., Blurton-Jones, M., and Laferla, F. M. (2010). Oligemic hypoperfusion differentially affects tau and amyloid- $\beta$. Am. J. Pathol. 177, 300-310. doi: 10.2353/ajpath.2010.090750

Kokjohn, T. A., Van Vickle, G. D., Maarouf, C. L., Kalback, W. M., Hunter, J. M., Daugs, I. D., et al. (2011). Chemical characterization of pro-inflammatory amyloid- $\beta$ peptides in human atherosclerotic lesions and platelets. Biochim. Biophys. Acta 1812, 1508-1514. doi: 10.1016/j.bbadis.2011.07.004

Korivi, M., Hou, C. W., Chen, C. Y., Lee, J.P., Kesireddy, S.R., and Kuo, C. H (2010). Angiogenesis: role of exercise training and aging. Adapt. Med. 2, 29-41. doi: 10.4247/AM.2010.ABA005

Korte, N., Nortley, R., and Attwell, D. (2020). Cerebral blood flow decrease as an early pathological mechanism in Alzheimer's disease. Acta Neuropathol. 140, 793-810. doi: 10.1007/s00401-020-02215-w

Kosik, K. S. (2013). Diseases: study neuron networks to tackle Alzheimer's. Nature 503, 31-32. doi: 10.1038/503031a

Kövari, E., Herrmann, F. R., Hof, P. R., and Bouras, C. (2013). The relationship between cerebral amyloid angiopathy and cortical microinfarcts in brain ageing and Alzheimer's disease. Neuropathol. Appl. Neurobiol. 39, 498-509. doi: $10.1111 /$ nan. 12003

Kress, B. T., Iliff, J. J., Xia, M., Wang, M., Wei, H. S., Zeppenfeld, D., et al. (2014). Impairment of paravascular clearance pathways in the aging brain. Ann. Neurol. 76, 845-861. doi: 10.1002/ana.24271

Krstic, D., Madhusudan, A., Doehner, J., Vogel, P., Notter, T., Imhof, C., et al. (2012). Systemic immune challenges trigger and drive Alzheimer-like neuropathology in mice. J. Neuroinflammation 9:151. doi: 10.1186/1742-2094-9-151

Krucker, T., Schuler, A., Meyer, E. P., Staufenbiel, M., and Beckmann, N. (2004). Magnetic resonance angiography and vascular corrosion casting as tools in biomedical research: application to transgenic mice modeling Alzheimer's disease. Neurol. Res. 26, 507-516. doi: 10.1179/016164104225016281

Kuchibhotla, K. V., Goldman, S. T., Lattarulo, C. R., Wu, H. Y., Hyman, B. T., and Bacskai, B. J. (2008). A $\beta$ plaques lead to aberrant regulation of calcium homeostasis in vivo resulting in structural and functional disruption of neuronal networks. Neuron 59, 214-225. doi: 10.1016/j.neuron.2008. 06.008

Kunkle, B. W., Grenier-Boley, B., Sims, R., Bis, J. C., Damotte, V., Naj, A. C., et al. (2019). Genetic meta-analysis of diagnosed Alzheimer's disease identifies new risk loci and implicates $\mathrm{A} \beta$, tau, immunity and lipid processing. Nat. Genet. 51, 414-430. doi: 10.1038/s41588-019-0358-2

Kyrtsos, C. R., and Baras, J. S. (2015). Modeling the role of the glymphatic pathway and cerebral blood vessel properties in Alzheimer's disease pathogenesis. PLoS One 10:e139574. doi: 10.1371/journal.pone.0139574

La Joie, R., Visani, A. V., Baker, S. L., Brown, J. A., Bourakova, V., Cha, J., et al.. (2020). Prospective longitudinal atrophy in Alzheimer's disease correlates with the intensity and topography of baseline tau-PET. Sci. Transl. Med. 12:eaau5732. doi: 10.1126/scitranslmed.aau5732

Lacalle-Aurioles, M., Mateos-Pérez, J. M., Guzmán-De-Villoria, J. A., Olazarán, J., Cruz-Orduña, I., Alemán-Gómez, Y., et al. (2014). Cerebral blood flow is an earlier indicator of perfusion abnormalities than cerebral blood volume in Alzheimer's disease. J. Cereb. Blood Flow Metab. 34, 654-659. doi: $10.1038 /$ jcbfm.2013.241

Lai, A. Y., Dorr, A., Thomason, L. A., Koletar, M. M., Sled, J. G., Stefanovic, B., et al. (2015). Venular degeneration leads to vascular dysfunction in a transgenic model of Alzheimer's disease. Brain 138(Pt 4), 1046-1058. doi: 10.1093/brain/awv023

Lanoiselée, H. M., Nicolas, G., Wallon, D., Rovelet-Lecrux, A., Lacour, M., Rousseau, S., et al. (2017). APP, PSEN1, and PSEN2 mutations in early-onset Alzheimer disease: a genetic screening study of familial and sporadic cases. PLoS Med. 14:e1002270. doi: 10.1371/journal.pmed.1002270

Lapenna, A., De Palma, M., and Lewis, C. E. (2018). Perivascular macrophages in health and disease. Nat. Rev. Immunol. 18, 689-702. doi: 10.1038/s41577-018-0056-9

Lathe, R., Sapronova, A., and Kotelevtsev, Y. (2014). Atherosclerosis and Alzheimer-diseases with a common cause? Inflammation, oxysterols, vasculature. BMC Geriatr. 14:36. doi: 10.1186/1471-2318-14-36

Lazic, D., Sagare, A. P., Nikolakopoulou, A. M., Griffin, J. H., Vassar, R., and Zlokovic, B. V. (2019). 3K3A-activated protein C blocks amyloidogenic BACE1 pathway and improves functional outcome in mice. J. Exp. Med. 216, 279-293. doi: $10.1084 /$ jem.20181035

Lewis, J., Dickson, D. W., Lin, W. L., Chisholm, L., Corral, A., Jones, G., et al. (2001). Enhanced neurofibrillary degeneration in transgenic mice expressing mutant tau and APP. Science 293, 1487-1491. doi: 10.1126/science.1058189

Li, B., Esipova, T. V., Sencan, I., Kil,iç, K., Fu, B., Desjardins, M., et al. (2019). More homogeneous capillary flow and oxygenation in deeper cortical layers correlate with increased oxygen extraction. Elife 8:e42299. doi: 10.7554/eLife.42299

Li, F., Abuarab, N., and Sivaprasadarao, A. (2017a). TRPM2: Shredding the mitochondrial network. Channels (Austin) 11, 507-509. doi: 10.1080/19336950.2017.1376982

Li, F., Munsey, T. S., and Sivaprasadarao, A. (2017b). TRPM2-mediated rise in mitochondrial Zn. Cell Death Differ. 24, 1999-2012. doi: 10.1038/cdd.2017.118

Li, F., Wong, R., Luo, Z., Du, L., Turlova, E., Britto, L. R. G., et al. (2019). Neuroprotective effects of AG490 in neonatal hypoxic-ischemic brain injury. Mol. Neurobiol. 56, 8109-8123. doi: 10.1007/s12035-019-01656-Z

Li, X., and Jiang, L. H. (2018). Multiple molecular mechanisms form a positive feedback loop driving amyloid $\beta 42$ peptide-induced neurotoxicity via activation of the TRPM2 channel in hippocampal neurons. Cell Death Dis. 9:195. doi: 10.1038/s41419-018-0270-1

Liebmann, T., Renier, N., Bettayeb, K., Greengard, P., Tessier-Lavigne, M., and Flajolet, M. (2016). Three-dimensional study of Alzheimer's disease hallmarks using the iDISCO clearing method. Cell Rep. 16, 1138-1152. doi: 10.1016/j.celrep.2016.06.060

Lim, G. P., Yang, F., Chu, T., Chen, P., Beech, W., Teter, B., et al. (2000). Ibuprofen suppresses plaque pathology and inflammation in a mouse model for Alzheimer's disease. J. Neurosci. 20, 5709-5714. doi: 10.1523/JNEUROSCI.20-15-05709.2000

Linse, S., Cabaleiro-Lago, C., Xue, W. F., Lynch, I., Lindman, S., Thulin, E., et al. (2007). Nucleation of protein fibrillation by nanoparticles. Proc. Natl. Acad. Sci. U. S. A. 104, 8691-8696. doi: 10.1073/pnas.0701250104

Liu, P. P., Xie, Y., Meng, X. Y., and Kang, J. S. (2019). History and progress of hypotheses and clinical trials for Alzheimer's disease. Signal Transduct. Target Ther. 4:29. doi: 10.1038/s41392-019-0063-8

Lovestone, S., Boada, M., Dubois, B., Hüll, M., Rinne, J. O., Huppertz, H. J., et al. (2015). A phase II trial of tideglusib in Alzheimer's disease. J. Alzheimers Dis. 45, 75-88. doi: 10.3233/JAD-141959

Lu, X., Moeini, M., Li, B., Lu, Y., Damseh, R., Pouliot, P., et al. (2019). A pilot study investigating changes in capillary hemodynamics and its modulation by exercise in the APP-PS1 Alzheimer mouse model. Front. Neurosci. 13:1261. doi: 10.3389/fnins.2019.01261

Luppi, C., Fioravanti, M., Bertolini, B., Inguscio, M., Grugnetti, A., Guerriero, F., et al. (2009). Growth factors decrease in subjects with mild to moderate Alzheimer's disease (AD): potential correction with dehydroepiandrosterone-sulphate (DHEAS). Arch. Gerontol. Geriatr. 49, 173-184. doi: 10.1016/j.archger.2009.09.027

Madav, Y., Wairkar, S., and Prabhakar, B. (2019). Recent therapeutic strategies targeting beta amyloid and tauopathies in Alzheimer's disease. Brain Res. Bull. 146, 171-184. doi: 10.1016/j.brainresbull.2019.01.004 
Maki, P. M., and Resnick, S. M. (2000). Longitudinal effects of estrogen replacement therapy on PET cerebral blood flow and cognition. Neurobiol. Aging 21, 373-383. doi: 10.1016/S0197-4580(00)00123-8

Makin, S. (2018). The amyloid hypothesis on trial. Nature 559, S4-S7. doi: 10.1038/d41586-018-05719-4

Maliszewska-Cyna, E., Vecchio, L. M., Thomason, L. A. M., Oore, J. J., Steinman, J., Joo, I. L., et al. (2020). The effects of voluntary running on cerebrovascular morphology and spatial short-term memory in a mouse model of amyloidosis. Neuroimage 222:117269. doi: 10.1016/j.neuroimage.2020.1 17269

Mandrekar-Colucci, S., and Landreth, G. E. (2010). Microglia and inflammation in Alzheimer's disease. CNS Neurol. Disord. Drug Targets 9, 156-167. doi: $10.2174 / 187152710791012071$

Mawuenyega, K. G., Sigurdson, W., Ovod, V., Munsell, L., Kasten, T., Morris, J. C., et al. (2010). Decreased clearance of CNS beta-amyloid in Alzheimer's disease. Science 330:1774. doi: 10.1126/science.1197623

Meyer, E. P., Ulmann-Schuler, A., Staufenbiel, M., and Krucker, T. (2008). Altered morphology and $3 \mathrm{D}$ architecture of brain vasculature in a mouse model for Alzheimer's disease. Proc. Natl. Acad. Sci. U. S. A. 105, 3587-3592. doi: 10.1073/pnas.0709788105

Miners, J. S., Schulz, I., and Love, S. (2018). Differing associations between $\mathrm{A} \beta$ accumulation, hypoperfusion, blood-brain barrier dysfunction and loss of PDGFRB pericyte marker in the precuneus and parietal white matter in Alzheimer's disease. J. Cereb. Blood Flow Metab. 38, 103-115. doi: $10.1177 / 0271678 X 17690761$

Miyakawa, T. (1997). Electron microscopy of amyloid fibrils and microvessels. Ann. N. Y. Acad. Sci. 826, 25-34. doi: 10.1111/j.1749-6632.1997.tb48458.x

Montagne, A., Nation, D. A., Sagare, A. P., Barisano, G., Sweeney, M. D., Chakhoyan, A., et al. (2020). APOE4 leads to blood-brain barrier dysfunction predicting cognitive decline. Nature 581, 71-76. doi: 10.1038/s41586-020-2247-3

Montagne, A., Nikolakopoulou, A. M., Zhao, Z., Sagare, A. P., Si, G., Lazic, D., et al. (2018). Pericyte degeneration causes white matter dysfunction in the mouse central nervous system. Nat. Med. 24, 326-337. doi: 10.1038/nm.4482

Mosconi, L., Rahman, A., Diaz, I., Wu, X., Scheyer, O., Hristov, H. W., et al. (2018). Increased Alzheimer's risk during the menopause transition: a 3-year longitudinal brain imaging study. PLoS One 13:e0207885. doi: 10.1371/journal.pone.0207885

Mucke, L. (2009). Neuroscience: Alzheimer's disease. Nature 461, 895-897. doi: $10.1038 / 461895$ a

Musiek, E. S., and Holtzman, D. M. (2012). Origins of Alzheimer's disease: reconciling cerebrospinal fluid biomarker and neuropathology data regarding the temporal sequence of amyloid-beta and tau involvement. Curr. Opin. Neurol. 25, 715-720. doi: 10.1097/WCO.0b013e32835a30f4

Naj, A. C., Jun, G., Beecham, G. W., Wang, L. S., Vardarajan, B. N., Buros, J., et al. (2011). Common variants at MS4A4/MS4A6E, CD2AP, CD33 and EPHA1 are associated with late-onset Alzheimer's disease. Nat. Genet. 43, 436-441. doi: 10.1038/ng.801

Nation, D. A., Sweeney, M. D., Montagne, A., Sagare, A. P., D’Orazio, L. M., Pachicano, M., et al. (2019). Blood-brain barrier breakdown is an early biomarker of human cognitive dysfunction. Nat. Med. 25, 270-276. doi: 10.1038/s41591-018-0297-y

Nielsen, R. B., Egefjord, L., Angleys, H., Mouridsen, K., Gejl, M., Møller, A., et al. (2017). Capillary dysfunction is associated with symptom severity and neurodegeneration in Alzheimer's disease. Alzheimers Dement. 13, 1143-1153. doi: 10.1016/j.jalz.2017.02.007

Niwa, K., Carlson, G. A., and Iadecola, C. (2000). Exogenous A B1-40 reproduces cerebrovascular alterations resulting from amyloid precursor protein overexpression in mice. J. Cereb. Blood Flow Metab. 20, 1659-1668. doi: 10.1097/00004647-200012000-00005

Niwa, K., Kazama, K., Younkin, S. G., Carlson, G. A., and Iadecola, C. (2002). Alterations in cerebral blood flow and glucose utilization in mice overexpressing the amyloid precursor protein. Neurobiol. Dis. 9, 61-68. doi: 10.1006/nbdi.2001.0460

Nortley, R., Korte, N., Izquierdo, P., Hirunpattarasilp, C., Mishra, A., Jaunmuktane, Z., et al. (2019). Amyloid $\beta$ oligomers constrict human capillaries in Alzheimer's disease via signaling to pericytes. Science 365:eaav9518. doi: $10.1126 /$ science.aav9518
Ostapchenko, V. G., Chen, M., Guzman, M. S., Xie, Y. F., Lavine, N., Fan, J., et al. (2015). The transient receptor potential melastatin 2 (TRPM2) channel contributes to $\beta$-amyloid oligomer-related neurotoxicity and memory impairment. J. Neurosci. 35, 15157-15169. doi: 10.1523/JNEUROSCI.4081-14.2015

Østergaard, L., Aamand, R., Gutiérrez-Jiménez, E., Ho, Y. C., and Blicher, J. U., Madsen, S. M., et al. (2013). The capillary dysfunction hypothesis of Alzheimer's disease. Neurobiol. Aging 34, 1018-1031. doi: 10.1016/j.neurobiolaging.2012.09.011

Østergaard, L., Jespersen, S. N., Engedahl, T., Gutiérrez Jiménez, E., and Ashkanian, M., Hansen, M. B., et al. (2015). Capillary dysfunction: its detection and causative role in dementias and stroke. Curr. Neurol. Neurosci. Rep. 15:37. doi: 10.1007/s11910-015-0557-x

Ostrowski, P. P., Barszczyk, A., Forstenpointner, J., Zheng, W., and Feng, Z. P. (2016). Meta-analysis of serum insulin-like growth factor 1 in Alzheimer's disease. PLoS One 11:e0155733. doi: 10.1371/journal.pone.0155733

Paris, D., Patel, N., DelleDonne, A., Quadros, A., Smeed, R., and Mullan, M. (2004a). Impaired angiogenesis in a transgenic mouse model of cerebral amyloidosis. Neurosci. Lett. 366, 80-85. doi: 10.1016/j.neulet.200 4.05.017

Paris, D., Quadros, A., Humphrey, J., Patel, N., Crescentini, R., Crawford, F., et al. (2004b). Nilvadipine antagonizes both $A \beta$ vasoactivity in isolated arteries, and the reduced cerebral blood flow in APPsw transgenic mice. Brain Res. 999, 53-61. doi: 10.1016/j.brainres.2003.11.061

Paris, D., Townsend, K., Quadros, A., Humphrey, J., Sun, J., Brem, S., et al. (2004c). Inhibition of angiogenesis by Abeta peptides. Angiogenesis, 7, 75-85. doi: 10.1023/B:AGEN.0000037335.17717.bf

Park, J., Wetzel, I., Marriott, I., Dréau, D., D’Avanzo, C., Kim, D. Y., et al. (2018). A 3D human triculture system modeling neurodegeneration and neuroinflammation in Alzheimer's disease. Nat. Neurosci. 21, 941-951. doi: 10.1038/s41593-018-0175-4

Park, L., Uekawa, K., Garcia-Bonilla, L., Koizumi, K., Murphy, M., Pistik, R., et al. (2017). Brain perivascular macrophages initiate the neurovascular dysfunction of Alzheimer A $\beta$ peptides. Circ. Res. 121, 258-269. doi: 10.1161/CIRCRESAHA.117.311054

Park, L., Wang, G., Moore, J., Girouard, H., Zhou, P., Anrather, J., et al. (2014). The key role of transient receptor potential melastatin-2 channels in amyloid- $\beta$-induced neurovascular dysfunction. Nat. Commun. 5:5318. doi: $10.1038 /$ ncomms 6318

Patton, R. L., Kalback, W. M., Esh, C. L., Kokjohn, T. A., Van Vickle, G. D., Luehrs, D. C., et al. (2006). Amyloid-beta peptide remnants in AN-1792immunized Alzheimer's disease patients: a biochemical analysis. Am. J. Pathol. 169, 1048-1063. doi: 10.2353/ajpath.2006.060269

Peeples, L. (2020). News feature: how air pollution threatens brain health. Proc. Natl. Acad. Sci. U. S. A. 117, 13856-13860. doi: 10.1073/pnas.2008940117

Peng, W., Achariyar, T. M., Li, B., Liao, Y., Mestre, H., Hitomi, E., et al. (2016). Suppression of glymphatic fluid transport in a mouse model of Alzheimer's disease. Neurobiol. Dis. 93, 215-225. doi: 10.1016/j.nbd.201 6.05 .015

Perez, F. P., Bose, D., Maloney, B., Nho, K., Shah, K., and Lahiri, D. K. (2014). Late-onset Alzheimer's disease, heating up and foxed by several proteins: pathomolecular effects of the aging process. J. Alzheimers Dis. 40, 1-17. doi: 10.3233/JAD-131544

Perlmutter, L. S., Chui, H. C., Saperia, D., and Athanikar, J. (1990). Microangiopathy and the colocalization of heparan sulfate proteoglycan with amyloid in senile plaques of Alzheimer's disease. Brain Res. 508, 13-19. doi: 10.1016/0006-8993(90)91111-S

Preston, S. D., Steart, P. V., Wilkinson, A., Nicoll, J. A., and Weller, R. O. (2003). Capillary and arterial cerebral amyloid angiopathy in Alzheimer's disease: defining the perivascular route for the elimination of amyloid beta from the human brain. Neuropathol. Appl. Neurobiol. 29, 106-117. doi: 10.1046/j.1365-2990.2003.00424.x

Raja, R., Rosenberg, G. A., and Caprihan, A. (2018). MRI measurements of Blood-Brain Barrier function in dementia: a review of recent studies. Neuropharmacology. 134(Pt B), 259-271. doi: 10.1016/j.neuropharm.2017.10.034

Ramanathan, A., Nelson, A. R., Sagare, A. P., and Zlokovic, B. V. (2015). Impaired vascular-mediated clearance of brain amyloid beta in Alzheimer's disease: 
the role, regulation and restoration of LRP1. Front. Aging Neurosci. 7:136. doi: 10.3389/fnagi.2015.00136

Rasgon, N. L., Geist, C. L., Kenna, H. A., Wroolie, T. E., Williams, K. E., and Silverman, D. H. (2014). Prospective randomized trial to assess effects of continuing hormone therapy on cerebral function in postmenopausal women at risk for dementia. PLoS One 9:e89095. doi: 10.1371/journal.pone.0089095

Reeves, B. C., Karimy, J. K., Kundishora, A. J., Mestre, H., Cerci, H. M., Matouk, C., et al. (2020). Glymphatic system impairment in Alzheimer's disease and idiopathic normal pressure hydrocephalus. Trends Mol. Med. 26, 285-295. doi: 10.1016/j.molmed.2019.11.008

Religa, P., Cao, R., Religa, D., Xue, Y., Bogdanovic, N., Westaway, D., et al. (2013). VEGF significantly restores impaired memory behavior in Alzheimer's mice by improvement of vascular survival. Sci. Rep. 3:2053. doi: 10.1038/srep02053

Rius-Pérez, S., Tormos, A. M., Pérez, S., and Taléns-Visconti, R. (2018). Vascular pathology: cause or effect in Alzheimer disease? Neurologia 33, 112-120. doi: 10.1016/j.nrleng.2015.07.008

Rivard, A., Fabre, J. E., Silver, M., Chen, D., Murohara, T., Kearney, M., et al. (1999). Age-dependent impairment of angiogenesis. Circulation 99, 111-120. doi: 10.1161/01.CIR.99.1.111

Safieh, M., Korczyn, A. D., and Michaelson, D. M. (2019). ApoE4: an emerging therapeutic target for Alzheimer's disease. BMC Med. 17:64. doi: 10.1186/s12916-019-1299-4

Sagare, A. P., Bell, R. D., and Zlokovic, B. V. (2012). Neurovascular dysfunction and faulty amyloid $\beta$-peptide clearance in Alzheimer disease. Cold Spring Harb. Perspect. Med. 2:a011452. doi: 10.1101/cshperspect.a011452

Sasaguri, H., Nilsson, P., Hashimoto, S., Nagata, K., Saito, T., De Strooper, B., et al. (2017). APP mouse models for Alzheimer's disease preclinical studies. EMBO J. 36, 2473-2487. doi: 10.15252/embj.201797397

Savolainen-Peltonen, H., Rahkola-Soisalo, P., Hoti, F., Vattulainen, P., Gissler, M., Ylikorkala, O., et al. (2019). Use of postmenopausal hormone therapy and risk of Alzheimer's disease in Finland: nationwide case-control study. BMJ 364:1665. doi: $10.1136 / \mathrm{bmj} .1665$

Scheibel, A. B., Duong, T. H., and Jacobs, R. (1989). Alzheimer's disease as a capillary dementia. Ann. Med. 21, 103-107. doi: 10.3109/07853898909149194

Scheiblich, H., Trombly, M., Ramirez, A., and Heneka, M. T. (2020). Neuroimmune connections in aging and neurodegenerative diseases. Trends Immunol. 41, 300-312. doi: 10.1016/j.it.2020.02.002

Schenk, D., Barbour, R., Dunn, W., Gordon, G., Grajeda, H., Guido, T., et al. (1999). Immunization with amyloid- $\beta$ attenuates Alzheimer-disease-like pathology in the PDAPP mouse. Nature 400, 173-177. doi: 10.1038/22124

Scheyer, O., Rahman, A., Hristov, H., Berkowitz, C., Isaacson, R. S., Diaz Brinton, R., et al. (2018). Female sex and Alzheimer's risk: the menopause connection. J. Prev. Alzheimers Dis. 5, 225-230. doi: 10.14283/jpad.2018.34

Schmid, F., Tsai, P. S., Kleinfeld, D., Jenny, P., and Weber, B. (2017). Depthdependent flow and pressure characteristics in cortical microvascular networks. PLoS Comput. Biol. 13:e1005392. doi: 10.1371/journal.pcbi.1005392

Schultheiss, C., Blechert, B., Gaertner, F. C., Drecoll, E., Mueller, J., Weber, G. F., et al. (2006). In vivo characterization of endothelial cell activation in a transgenic mouse model of Alzheimer's disease. Angiogenesis 9, 59-65. doi: 10.1007/s10456-006-9030-4

Selkoe, D. J. (2011). Resolving controversies on the path to Alzheimer's therapeutics. Nat. Med. 17, 1060-1065. doi: 10.1038/nm.2460

Selkoe, D. J. (2019). Early network dysfunction in Alzheimer's disease. Science 365, 540-541. doi: 10.1126/science.aay5188

Selkoe, D. J., and Hardy, J. (2016). The amyloid hypothesis of Alzheimer's disease at 25 years. EMBO Mol. Med. 8, 595-608. doi: 10.15252/emmm.201606210

Serenó, L., Coma, M., Rodríguez, M., Sánchez-Ferrer, P., Sánchez, M. B., Gich, I., et al. (2009). A novel GSK-3 $\beta$ inhibitor reduces Alzheimer's pathology and rescues neuronal loss in vivo. Neurobiol. Dis. 35, 359-367. doi: 10.1016/j.nbd.2009.05.025

Sevigny, J., Chiao, P., Bussière, T., Weinreb, P. H., Williams, L., Maier, M., et al. (2016). The antibody aducanumab reduces $A \beta$ plaques in Alzheimer's disease. Nature 537, 50-56. doi: 10.1038/nature19323

Shin, Y., Choi, S. H., Kim, E., Bylykbashi, E., Kim, J. A., Chung, S., et al. (2019). Blood-brain barrier dysfunction in a $3 \mathrm{D}$ in vitro model of Alzheimer's disease. Adv. Sci. (Weinh) 6:1900962. doi: 10.1002/advs.201900962

Silva, M. V. F., Loures, C. M. G., Alves, L. C. V., de Souza, L. C., Borges, K. B. G., and Carvalho, M. D. G. (2019). Alzheimer's disease: risk factors and potentially protective measures. J. Biomed. Sci. 26:33. doi: 10.1186/s12929-019 0524-y

Silverberg, G. D., Messier, A. A., Miller, M. C., Machan, J. T., Majmudar, S. S., Stopa, E. G., et al. (2010). Amyloid efflux transporter expression at the blood-brain barrier declines in normal aging. J. Neuropathol. Exp. Neurol. 69, 1034-1043. doi: 10.1097/NEN.0b013e3181f46e25

Smith, C. D., Andersen, A. H., Kryscio, R. J., Schmitt, F. A., Kindy, M. S., Blonder, L. X., et al. (1999). Altered brain activation in cognitively intact individuals at high risk for Alzheimer's disease. Neurology 53, 1391-1396. doi: 10.1212/WNL.53.7.1391

Smith, L. M., and Strittmatter, S. M. (2017). Binding sites for amyloid- $\beta$ oligomers and synaptic toxicity. Cold Spring Harb. Perspect. Med. 7:a024075. doi: 10.1101/cshperspect.a024075

Stakos, D. A., Stamatelopoulos, K., Bampatsias, D., Sachse, M., Zormpas, E., Vlachogiannis, N. I., et al. (2020). The Alzheimer's disease amyloid-beta hypothesis in cardiovascular aging and disease: JACC focus seminar. J. Am. Coll. Cardiol. 75, 952-967. doi: 10.1016/j.jacc.2019.12.033

Starkus, J. G., Poerzgen, P., Layugan, K., Kawabata, K. G., Goto, J. I., Suzuki, S., et al. (2017). Scalaradial is a potent inhibitor of transient receptor potential melastatin 2 (TRPM2) ion channels. J. Nat. Prod. 80, 2741-2750. doi: 10.1021/acs.jnatprod.7b00515

Steinman, J., Cahill, L. S., Koletar, M. M., Stefanovic, B., and Sled, J. G. (2019). Acute and chronic stage adaptations of vascular architecture and cerebral blood flow in a mouse model of TBI. Neuroimage 202:116101. doi: 10.1016/j.neuroimage.2019.116101

Steinman, J., Koletar, M. M., Stefanovic, B., and Sled, J. G. (2017). $3 \mathrm{D}$ morphological analysis of the mouse cerebral vasculature: comparison of in vivo and ex vivo methods. PLoS One 12:e0186676. doi: 10.1371/journal.pone. 0186676

Strickland, S. (2018). Blood will out: vascular contributions to Alzheimer's disease. J. Clin. Invest. 128, 556-563. doi: 10.1172/JCI97509

Suárez-Calvet, M., Araque Caballero, M., Kleinberger, G., Bateman, R. J., Fagan, A. M., Morris, J. C., et al. (2016). Early changes in CSF sTREM2 in dominantly inherited Alzheimer's disease occur after amyloid deposition and neuronal injury. Sci. Transl. Med. 8:369ra178. doi: 10.1126/scitranslmed.aag1767

Sun, Z. (2015). Aging, arterial stiffness, and hypertension. Hypertension 65, 252-256. doi: 10.1161/HYPERTENSIONAHA.114.03617

Sweeney, M. D., Zhao, Z., Montagne, A., Nelson, A. R., and Zlokovic, B. V. (2019). Blood-brain barrier: from physiology to disease and back. Physiol. Rev. 99, 21-78. doi: 10.1152/physrev.00050.2017

Swerdlow, R. H., Burns, J. M., and Khan, S. M. (2014). The Alzheimer's disease mitochondrial cascade hypothesis: progress and perspectives. Biochim. Biophys. Acta 1842, 1219-1231. doi: 10.1016/j.bbadis.2013.09.010

Tarantini, S., Tucsek, Z., Valcarcel-Ares, M. N., Toth, P., Gautam, T., Giles, C. B., et al. (2016). Circulating IGF-1 deficiency exacerbates hypertensioninduced microvascular rarefaction in the mouse hippocampus and retrosplenial cortex: implications for cerebromicrovascular and brain aging. Age (Dordr) 38, 273-289. doi: 10.1007/s11357-016-9931-0

Tarasoff-Conway, J. M., Carare, R. O., Osorio, R. S., Glodzik, L., Butler, T., Fieremans, E., et al. (2015). Clearance systems in the brainimplications for Alzheimer disease. Nat. Rev. Neurol. 11, 457-470. doi: 10.1038/nrneurol.2015.119

Thal, D. R., Capetillo-Zarate, E., Larionov, S., Staufenbiel, M., Zurbruegg, S., and Beckmann, N. (2009). Capillary cerebral amyloid angiopathy is associated with vessel occlusion and cerebral blood flow disturbances. Neurobiol. Aging 30, 1936-1948. doi: 10.1016/j.neurobiolaging.2008.01.017

Thal, D. R., Ghebremedhin, E., Rüb, U., Yamaguchi, H., Del Tredici, K., and Braak, H. (2002). Two types of sporadic cerebral amyloid angiopathy. J. Neuropathol. Exp. Neurol. 61, 282-293. doi: 10.1093/jnen/61.3.282

Thal, D. R., Griffin, W. S., de Vos, R. A., and Ghebremedhin, E. (2008). Cerebral amyloid angiopathy and its relationship to Alzheimer's disease. Acta Neuropathol. 115, 599-609. doi: 10.1007/s00401-008-0366-2

Thomas, K. R., Bangen, K. J., Weigand, A. J., Edmonds, E. C., Wong, C. G., Cooper, S., et al. (2020). Objective subtle cognitive difficulties predict future amyloid accumulation and neurodegeneration. Neurology 94, e397e406. doi: 10.1212/WNL.0000000000008838

Tibolla, G., Norata, G. D., Meda, C., Arnaboldi, L., Uboldi, P., Piazza, F., et al. (2010). Increased atherosclerosis and vascular inflammation in APP 
transgenic mice with apolipoprotein E deficiency. Atherosclerosis 210, 78-87. doi: 10.1016/j.atherosclerosis.2009.10.040

Townsend, K. P., and Praticò, D. (2005). Novel therapeutic opportunities for Alzheimer's disease: focus on nonsteroidal anti-inflammatory drugs. FASEB J. 19, 1592-1601. doi: 10.1096/fj.04-3620rev

Turlova, E., Feng, Z. P., and Sun, H. S. (2018). The role of TRPM2 channels in neurons, glial cells and the blood-brain barrier in cerebral ischemia and hypoxia. Acta Pharmacol. Sin. 39, 713-721. doi: 10.1038/aps.2017.194

Turner, R. S., Hebron, M. L., Lawler, A., Mundel, E. E., Yusuf, N., Starr, J. N., et al. (2020). Nilotinib effects on safety, tolerability, and biomarkers in Alzheimer's disease. Ann. Neurol. 88, 183-194. doi: 10.1002/ana.25775

Ujiie, M., Dickstein, D. L., Carlow, D. A., and Jefferies, W. A. (2003). Blood-brain barrier permeability precedes senile plaque formation in an Alzheimer disease model. Microcirculation 10, 463-470. doi: 10.1080/mic.10.6.463.470

Vagnucci, A. H., and Li, W. W. (2003). Alzheimer's disease and angiogenesis. Lancet 361, 605-608. doi: 10.1016/S0140-6736(03)12521-4

Van Dam, D., Coen, K., and De Deyn, P. P. (2010). Ibuprofen modifies cognitive disease progression in an Alzheimer's mouse model. J. Psychopharmacol. 24, 383-388. doi: 10.1177/0269881108097630

Vandenberghe, R., Rinne, J. O., Boada, M., Katayama, S., Scheltens, P., Vellas, B., et al. (2016). Bapineuzumab for mild to moderate Alzheimer's disease in two global, randomized, phase 3 trials. Alzheimers Res. Ther. 8:18. doi: 10.1186/s13195-016-0189-7

Vandenberghe, R., and Tournoy, J. (2005). Cognitive aging and Alzheimer's disease. Postgrad. Med. J. 81, 343-352. doi: 10.1136/pgmj.2004.028290

Venegas, C., Kumar, S., Franklin, B. S., Dierkes, T., Brinkschulte, R., Tejera, D., et al. (2017). Microglia-derived ASC specks cross-seed amyloid- $\beta$ in Alzheimer's disease. Nature 552, 355-361. doi: 10.1038/nature25158

Vogel, J., Gehrig, M., Kuschinsky, W., and Marti, H. H. (2004). Massive inborn angiogenesis in the brain scarcely raises cerebral blood flow. J. Cereb. Blood Flow Metab. 24, 849-859. doi: 10.1097/01.WCB.0000126564.89011.11

Wåhlin, A., and Nyberg, L. (2019). At the heart of cognitive functioning in aging. Trends Cogn. Sci. 23, 717-720. doi: 10.1016/j.tics.2019.06.004

Walsh, D. M., and Selkoe, D. J. (2020). Amyloid $\beta$-protein and beyond: the path forward in Alzheimer's disease. Curr. Opin. Neurobiol. 61, 116-124. doi: 10.1016/j.conb.2020.02.003

Wang, L., Du, Y., Wang, K., Xu, G., Luo, S., and He, G. (2016). Chronic cerebral hypoperfusion induces memory deficits and facilitates $\mathrm{A} \beta$ generation in C57BL/6J mice. Exp Neurol. 283(Pt A), 353-364. doi: 10.1016/j.expneurol.2016.07.006

Wang, W. Y., Tan, M. S., Yu, J. T., and Tan, L. (2015). Role of pro-inflammatory cytokines released from microglia in Alzheimer's disease. Ann. Transl. Med. 3:136. doi: 10.3978/j.issn.2305-5839.2015.03.49

Wang, Y., Kilic, E., Kilic, U., Weber, B., Bassetti, C. L., Marti, H. H., et al. (2005). VEGF overexpression induces post-ischaemic neuroprotection, but facilitates haemodynamic steal phenomena. Brain 128(Pt 1), 52-63. doi: 10.1093/brain/awh325

Weller, R. O., Boche, D., and Nicoll, J. A. (2009). Microvasculature changes and cerebral amyloid angiopathy in Alzheimer's disease and their potential impact on therapy. Acta Neuropathol. 118, 87-102. doi: 10.1007/s00401-009-0498-Z
Weller, R. O., Subash, M., Preston, S. D., Mazanti, I., and Carare, R. O. (2008). Perivascular drainage of amyloid-beta peptides from the brain and its failure in cerebral amyloid angiopathy and Alzheimer's disease. Brain Pathol. 18, 253-266. doi: 10.1111/j.1750-3639.2008.00133.x

Wilcock, D. M., Rojiani, A., Rosenthal, A., Subbarao, S., Freeman, M. J., Gordon, M. N., et al. (2004). Passive immunotherapy against A $\beta$ in aged APP-transgenic mice reverses cognitive deficits and depletes parenchymal amyloid deposits in spite of increased vascular amyloid and microhemorrhage. J. Neuroinflamm. 1:24. doi: 10.1186/1742-2094-1-24

Xu, Z., Xiao, N., Chen, Y., Huang, H., Marshall, C., Gao, J., et al. (2015). Deletion of aquaporin-4 in APP/PS1 mice exacerbates brain A $\beta$ accumulation and memory deficits. Mol. Neurodegener. 10:58. doi: 10.1186/s13024-0150056-1

Yan, Q., Zhang, J., Liu, H., Babu-Khan, S., Vassar, R., Biere, A. L., et al. (2003). Anti-inflammatory drug therapy alters beta-amyloid processing and deposition in an animal model of Alzheimer's disease. J. Neurosci. 23, 7504-7509. doi: 10.1523/JNEUROSCI.23-20-07504.2003

Yancopoulos, G. D., Davis, S., Gale, N. W., Rudge, J. S., Wiegand, S. J., and Holash, J. (2000). Vascular-specific growth factors and blood vessel formation. Nature 407, 242-248. doi: 10.1038/35025215

Yates, P. A., Desmond, P. M., Phal, P. M., Steward, C., Szoeke, C., Salvado, O., et al. (2014). Incidence of cerebral microbleeds in preclinical Alzheimer disease. Neurology 82, 1266-1273. doi: 10.1212/WNL.0000000000000285

Zetterberg, H., and Bendlin, B. B. (2020). Biomarkers for Alzheimer's diseasepreparing for a new era of disease-modifying therapies. Mol. Psychiatry. doi: 10.1038/s41380-020-0721-9

Zhang, Y., Chao, F. L., Zhang, L., Jiang, L., Zhou, C. N., Chen, L. M., Lu, W., Jiang, R., and Tang, Y. (2019). Quantitative study of the capillaries within the white matter of the Tg2576 mouse model of Alzheimer's disease. Brain Behav. 9:e01268. doi: 10.1002/brb3.1268

Zhao, L. (2019). CD33 in Alzheimer's disease - biology, pathogenesis, and therapeutics: a mini-review. Gerontology 65, 323-331. doi: 10.1159/000492596

Zlokovic, B. V. (2005). Neurovascular mechanisms of Alzheimer's neurodegeneration. Trends Neurosci, 28: 202-208. doi: 10.1016/j.tins.2005.02.001

Zott, B., Simon, M. M., Hong, W., Unger, F., Chen-Engerer, H. J., Frosch, M. P., Sakmann, B., Walsh, D. M., and Konnerth, A. (2019). A vicious cycle of $\beta$ amyloid-dependent neuronal hyperactivation. Science 365, 559-565. doi: 10.1126/science.aay0198

Conflict of Interest: The authors declare that the research was conducted in the absence of any commercial or financial relationships that could be construed as a potential conflict of interest.

Copyright (C) 2021 Steinman, Sun and Feng. This is an open-access article distributed under the terms of the Creative Commons Attribution License (CC BY). The use, distribution or reproduction in other forums is permitted, provided the original author(s) and the copyright owner(s) are credited and that the original publication in this journal is cited, in accordance with accepted academic practice. No use, distribution or reproduction is permitted which does not comply with these terms. 